Daniel G. Tracy (dtracy@illinois.edu) is Head, Scholarly Communication and Publishing at the University of Illinois at Urbana-Champaign.

Manuscript submitted February 15, 2018; returned to author for revision May 16, 2018; revised manuscript submitted July 15, 2018; accepted for publication December 31, 2018.

The author wishes to thank the University of Illinois at Urbana-Champaign's Library Assessment Committee for funding in support of this project. Thank you to Michael Norman in the library's Content Access Management unit for providing the necessary catalog data and to Esra Coskun for answering questions related to challenges with access to usage statistics. Special thanks also go to Jaena Manson for creating the combined data set and calculating initial frequency totals. Finally, thank you to colleagues who provided feedback on drafts, including Jamie Carlstone, Sarah Christensen, Megan Ozeran, Heather Simmons, Mara Thacker, and Jen-chien Yu.

\section{E-book Use over Time and across Vendors in an Interdisciplinary Field}

\section{Daniel G. Tracy}

This paper presents an analysis of e-book usage in one interdisciplinary research collection, for library and information science (LIS), at a large research institution. Drawing from the social sciences, humanities, and computer science, LIS exemplifies the challenge of analyzing use of interdisciplinary collections that cut across Library of Congress $(L C)$ class ranges normally used to analyze disciplinary differences in the existing literature. The analysis also explores use factors beyond $L C$ class that usage studies rarely examine, including genre and audience level, and changes in use over time across categories. This study contributes both to understanding the usage of LIS e-books as an exemplary interdisciplinary collection and to developing options for analyses of e-book collections that maximize the utility of usage reports despite their challenges. As e-book collections mature and the utility of comparing used versus unused titles wanes, such strategies will become necessary to make more nuanced decisions for e-book collections.

The present study analyzes Library and Information Science (LIS) e-book 1 collections usage data at a large research institution as an exploration of how e-book usage might be examined in more detail for individual disciplines, and in this case, a particularly dispersed discipline with content across different areas of the Library of Congress Classification (LCC). It also considers methods that might be adapted for overall collections analysis. The author seeks to consider temporal factors of e-book use that have not frequently been measured in e-book usage analysis.

This study pursues three interrelated questions in the course of analyzing these statistics. The first question establishes factors for comparison of relative use in the context of particular disciplinary collections, but which could also be used for general collections analysis:

1. What patterns of usage emerge for LIS e-book content in relation to: a) different subdisciplinary areas? b) different genres of book? and c) audience level for the text?

The second question seeks to expand analysis of e-book collections over time. Prior studies rarely examine change over time, and typically focus on all use within a particular set time period (often coinciding with a vendor trial). This lack reasonably derives in part from the relative youth of e-book collections; the present study explores a disciplinary area that made a relatively early conversion to e-book purchases at a large research university, and thus provides 
an opportunity to examine these temporal factors in an established e-book collection.

2. How does usage of LIS e-books vary across temporal dimensions, including semester-by-semester evolution of e-book use over a five-year period of significant growth in the e-book collection, and when considering use over the life of titles from the year of publication forward?

The third question seeks to test new ways of using e-book usage statistics provided under the primary standard for electronic resources statistics, COUNTER, which, as described in the literature review, poses substantial challenges for in-depth analysis.

3. Does our understanding of the patterns of use in the collection change when using different methods, including the common method of counting use versus non-use and alternate options such as creating categories of use (grouping titles that have use within a particular range) or analyzing the top quartile of used books?

While investigating these questions, the present study examines usage statistics from a large research institution with a major graduate program in library and information science and a related program in informatics, plus a significant group of active librarian-researchers. LIS as treated here is an interdisciplinary field that draws methodologies and publication patterns from the social sciences, humanities, and computer science (and sometimes other fields). LIS collection development funds at the institution serve researchers and students working in areas that extend beyond management of libraries, museums, and archives and development of related services. This includes areas such as history of the book, publishing, children's literature, and reading; the economics of information; historical and social aspects of information technologies; informatics; knowledge management; book arts; censorship; humancomputer interaction and user experience; and other fields. Some of these areas involve coordination of collection development with other subject selectors, and many of these areas are likely to be studied by patrons other than the faculty and students of the library and information science program or the library. This broad spread of disciplinary topics and approaches makes it a good candidate for examining usage in an interdisciplinary collection.

The study's implications are not limited to collections and services related to library and information science but also for how future e-book studies are conducted. The interdisciplinary breakdown of the collection suggests possible problems with how prior studies have divided up disciplinary categories, and studying usage patterns over time has potential to add nuance to collection development and management strategies for e-books as they become more established parts of the collections landscape.

\section{Literature Review}

Researchers studying e-book use have had to contend with the challenges of e-book usage reports, which sometimes are not provided forms that are compliant with COUNTER. Even when vendors do use COUNTER, they may implement the standard differently, leading to what Conyers et al. refer to as "a lack of clarity and consistency around treatment of usage data" that calls for better standards and implementation. ${ }^{1}$ Key issues include the lack of comparability between a counted e-book use and a print book checkout, or between e-book uses counted through COUNTER Book Report 1 (which reports uses of individual books in their entirety) and COUNTER Book Report 2 (which reports uses of sections of books), where the latter would presumably count more uses than the former if the same user engaged with multiple chapters of a title. Individual vendors may operationalize the same report to different results. Neither report can count uses that happen after a download occurs, and platforms with heavy digital rights management (DRM) that requires users to return to the platform for each reading, rather than download, will also produce larger use counts (unless the DRM prevents readers from returning). Some studies use transaction logs to conduct deeper analysis, and in a study of Ebook Library (EBL) transaction logs, Zhang, Niu, and Promann found that 8 percent of sessions included at least one download action. ${ }^{2}$ The author notes that EBL has since been absorbed, with ebrary, into ProQuest Ebook Central. This study refers to the platforms as they were called before this change.

Studies seeking a deeper understanding of use, and that lack access to more detailed transaction logs, avoid these problems by ignoring usage totals and counting only whether individual titles have been used. ${ }^{3}$ In one of the only studies to examine usage across time, Chrzastowski found a large increase in total uses across e-book collections at a large research institution between 2008 and 2011 and a smaller but substantial increase in the overall percentage of titles used in the same period for the four top vendors with comparable download/usage models. ${ }^{4}$ In some cases, studies also compare the relative extent of use of e-book subcategories (in terms of percent of titles used) to their overall size within the collection (for example by LC class range) to identify under- or over-performing categories of e-books.

Several studies that examined transaction logs revealed that much e-book use is either ephemeral or relates to quick browsing, a phenomenon Staiger identified in a 
review of the e-book literature as a "use rather than read" phenomenon. ${ }^{5}$ Zhang, Niu, and Promann calculated that 80 percent of reading sessions in EBL transaction logs in an eleven-month period included views of thirty pages or less. ${ }^{6}$ Likewise, Chrzastowski and Wiley found primarily use of sections of titles and cautioned against dismissing briefer "use" transactions since such uses may serve an important discovery and evaluation role for users. ${ }^{7}$

By extension, a relatively small number of users and books accounts for most uses and the most time spent using e-books. Ahmad, Brogan, and Johnstone investigated what they call "power user" behavior, finding for one set of EBL transaction logs that 1.32 percent of users accounted for 12.81 percent of book views, 12.06 percent of time spent browsing, 27.50 percent of time spend reading, and 27.81 percent of unique titles browsed or read. ${ }^{8}$

Beyond examining the overall growth in the use of e-books, e-book usage and transaction log studies have primarily focused on comparing interest in e-books across the academic disciplines, with LCC ranges serving as proxies for disciplines. An early report by the UK's Joint Information Systems Committee (JISC) National E-books Observatory Project discovered high use of business titles but very low use of engineering titles, and moderate use of media studies titles; but both business and engineering users spent more time in e-books whereas media studies users looked at more pages. ${ }^{9} \mathrm{Al}$, Soydal, and Tonta found the most use in medicine, followed by education and (unusual among e-book studies) language and literature..$^{10}$ Despite overall low use, Ahmand, Brogan, and Johnstone found that "power users" (those who use both many titles and significant portions of titles) tended to cluster in the health sciences, business, media, engineering, computing, education, and law. ${ }^{11}$ Levine-Clark analyzed global use of ebrary and EBL titles through transaction logs, and found disciplinary trends that diverged by type of use: STEM titles had the most page views per session and most downloads; arts and humanities users spent more time per session looking at less of the book, suggesting immersive reading; and the $\mathrm{T}$ and $\mathrm{F}$ LC classes (Technology and History of the Americas) showed use of the most pages per session, but while technology was heavily downloaded, history was not. ${ }^{12}$ He suggests the necessity of thinking of both intensive and extensive use of e-books across disciplines in different formats. Knowlton indicated heavier use of e-books in science and education and less by humanists and mathematicians. ${ }^{13}$

Within these disciplinary studies, LIS is usually treated as equivalent to the LC " $\mathrm{Z}$ " class range or grouped with several other class ranges into a set of "other" titles. LevineClark's global EBL and ebrary use analysis grouped Z, A, and $\mathrm{G}$ class ranges into such an "Other" category, effectively excluding them from parts of his analysis related to percentage of titles used. However, he includes all classes in his breakdown of intensive and extensive use: for EBL, Z titles performed on par in terms of number of titles used but saw more extensive than average use of copies and downloads, and lower than average use of views and prints; in ebrary, $\mathrm{Z}$ overperformed in terms of number of titles used, but had lower-than extensive use for all use types except downloads, which exceeded the norm. Analyses of $\mathrm{Z}$ titles have diverged otherwise. Linden, Sidman, and Tudesco showed underperformance by $\mathrm{Z}$ titles relative to the overall collection, but Knowlton showed approximately even use of $\mathrm{Z}$ e-books relative to the overall collection and a preference for e-books over print books for $\mathrm{Z}$ titles. ${ }^{14}$ Sprague and Hunter showed use of under 20 percent of $\mathrm{Z}$ titles in an early study. ${ }^{15}$ More recently, Mays demonstrated low levels of both "grazing" (short-term loans) and purchasing of e-books in a PDA program for $\mathrm{Z}$ titles, but her analysis is limited to raw totals and not relative use compared to presence in the collection. ${ }^{16}$ Regardless of findings, these studies all treat $\mathrm{Z}$ as equivalent to library science (or bibliography). This poses problems for understanding LIS collections both because the $\mathrm{Z}$ class range is split between LIS content areas and bibliographies for other disciplines, and because LIS content exists in a variety of other class ranges as a highly interdisciplinary subject area.

A smaller number of studies have compared e-book use across factors other than disciplines. Comparing use of essay collections and monographs, Freeman and Stewart Saunders found that readers of collections read more pages per book and more passages but cautioned that the difference was small. ${ }^{17}$ Horner found that use of university press titles was greater than other publisher e-books, a pattern that was not true for the same books in print. ${ }^{18}$

Vendor platforms can affect usage statistics in ways that extend beyond the problems of usage reporting methods. For example, factors tied to the user experience of the platform and the purchase model used with the vendor may impact use. Slater and Lamothe both found that use of title-by-title e-book selections outpaced titles purchased in packages, which at many libraries is part of agreements with different vendor platforms. ${ }^{19}$ More recently, Olney-Zide and Eiford performed a user study to identify preferred e-book platform features and analyzed how five major vendors compared on those factors and overall use. They found better user experience matched higher use of titles from particular vendors, both in terms of overall number of titles used and depth of use of those titles. ${ }^{20}$

\section{Method}

The head of cataloging provided a list of e-books in the library's collection from the local catalog (which includes all institutionally purchased e-book titles) that fell into any of 


\begin{tabular}{ll}
\hline & Table 1: Library of Congress Class Number Ranges in Study \\
\hline Class Range & Topical Coverage* \\
\hline AM [all] & Museums. Collectors and Collecting. \\
\hline AZ [all] & History of scholarship and learning, The humanities, Digital humanities. \\
\hline CD 921-988 & Archives. \\
\hline HC 79.155 & Economics of Information. \\
\hline HD 30.2 & Knowledge management, information management. \\
\hline HM 846-855 & Social aspects of information technology. \\
\hline KF1263.C65 & Computers and Privacy. \\
\hline KF2971-3194 & Copyright. \\
\hline $\begin{array}{l}\text { QA76 [select class } \\
\text { numbers] }\end{array}$ & Historical and social subtopics related to computer science. \\
\hline PN1009 & History of children's literature. \\
\hline T14-14.6 and T58.4-58.9 & Information technology, particularly philosophical and social aspects. \\
\hline Z1-1039 & Books, book history, libraries, bibliography [only works on the practice of]. \\
\hline ZA [all] & Information resources. \\
\hline *Topical coverage descriptions from Library of Congress documentation, but in some cases adjusted for local \\
collections emphasis.
\end{tabular}

multiple e-books on the same record (as part of a book series with links to each individual title). The student added or separated these titles into separate rows as necessary. Finally, the student added two hand-coded fields for each book to capture elements not included in typical catalog metadata that might play a role in use: 1) the text's genre, using a set of fixed codes provided by the researcher (Bibliography; Encyclopedia; Handbooks, Guides, and

the LC class number ranges used for the LIS approval plan plus select other areas purchased heavily for LIS but not on the LIS approval plan (see table 1). This allowed for inclusion of relevant titles outside the $\mathrm{Z}$ range plus exclusion of the subrange of $\mathrm{Z}$ devoted to national and non-LIS subject bibliographies, which are not collected by the LIS selector. Titles included e-books with an eligible class number listed in a second call number in the record and titles where the primary or only class number fell into eligible ranges. Any book with an eligible class number in either slot qualified for inclusion; if an e-book had two eligible class numbers, the first was used for analysis.

From this data set, titles prior to 2006 (older than ten years at the time of data collection) were eliminated to focus on a manageable time span with a relatively significant number of titles per year. Also excluded were titles with class numbers outside the appropriate ranges but included in the original data due to the search parameters. Because the method for pulling the eligible e-books might miss titles, the researcher compared the list to e-books purchased title-bytitle on approval since that process had begun for e-books in academic year 2010-2011 and added missing titles to the list. These mostly included titles outside the ranges listed in table 1 but relevant to the discipline and were grouped with the original list in broader class ranges (e.g., $\mathrm{P}$ instead of PN), with some classes assigned to an "Other" group for analysis due to very small numbers of texts.

The data set of titles included catalog metadata with some missing values and inconsistencies in representation of element values. A graduate student working with the researcher cleaned the data set by comparing data against catalog records and correcting missing or badly formatted values. This process led to discovery of titles with multiple e-book copies in the catalog from distinct vendors or
Technical Manuals; Proceedings; Textbook; Monographs; Collections; Other Reference; Reports; Other) and 2) the text's audience level as represented by the GOBI acquisitions platform used to order books (Advanced Academic, General Academic, Professional, Popular, or Basic), which indicates complexity and specialization of the content. The researcher resolved any ambiguity related to genre, missing audience levels, or other issues with metadata fields as the student tracked them and performed other random checks of the cleaned data during the process to ensure overall consistency.

The student merged the cleaned data set with monthly usage data from vendor usage statistics for the most recent five fiscal years as of the collection (July 2011 to June 2016). Merging is time intensive and cannot easily be automated: ISBNs accompanying usage statistics often do not match catalog records or even the ISBN on the e-book website. These statistics were largely from COUNTER Book Report 2 reports (downloads by section, henceforth BR2), but one vendor (EBSCO) provided COUNTER Book Report 1 (downloads by title, henceforth BR1), and two other vendors (Brill and Palgrave) provided both BR2 and BR1 reports due to different download options for titles. In some cases, codes were used in place of usage totals to indicate reasons for missing values or special cases of zero. For example, "U" was used to indicate instances where a title was published but not yet owned by the library. A " $\mathrm{Z}$ " was used for "implied zero": for example, when the COUNTER reports lacked totals for a title published and owned in a given time period, they implied there was zero use for the period of the report. Some vendors list zero-use titles explicitly, but the COUNTER standard requires only listing of used titles for a report period. BR2 and BR1 monthly totals were listed in separate sets of columns. 


\begin{tabular}{|c|c|c|}
\hline Vendor Type & Vendor/Platform & Titles \\
\hline \multirow{9}{*}{$\begin{array}{l}\text { Vendor platforms included } \\
\text { individually for analysis. }\end{array}$} & Brill & 33 \\
\hline & Ebrary & 364 \\
\hline & EBSCO & 501 \\
\hline & IEEE Xplore & 226 \\
\hline & InfoSci-Books & 225 \\
\hline & Safari & 114 \\
\hline & ScienceDirect & 91 \\
\hline & Springer & 604 \\
\hline & Wiley & 107 \\
\hline \multirow{17}{*}{$\begin{array}{l}\text { Vendor platforms grouped as } \\
\text { "Other" for analysis. }\end{array}$} & ABC-CLIO & 3 \\
\hline & Access Engineering Library & 1 \\
\hline & ACLS Humanities e-Book & 1 \\
\hline & American Chemical Society & 1 \\
\hline & AMS eBooks & 1 \\
\hline & ASME Digital Collection & 1 \\
\hline & Cambridge Books Online & 13 \\
\hline & CRCnetBASE & 13 \\
\hline & Credo Reference & 5 \\
\hline & De Gruyter & 14 \\
\hline & Gale Virtual Reference Library & 8 \\
\hline & JSTOR & 8 \\
\hline & Oxford & 7 \\
\hline & Palgrave Connect & 13 \\
\hline & Project Muse & 21 \\
\hline & Royal Society of Chemistry & 1 \\
\hline & World Scientific & 4 \\
\hline \multicolumn{2}{|l|}{ Subtotal } & 2380 \\
\hline \multirow{11}{*}{$\begin{array}{l}\text { Vendor platforms with no } \\
\text { ebook usage reports } \\
\text { available. Excluded from } \\
\text { analysis. }\end{array}$} & ACM Digital Library & 7 \\
\hline & ARL Digital Publications & 53 \\
\hline & DOAB & 30 \\
\hline & $\mathrm{EBL}$ & 5 \\
\hline & HathiTrust Digital Library & 1 \\
\hline & Knovel & 2 \\
\hline & Morgan \& Claypool & 42 \\
\hline & National Geographic Virtual Library & 1 \\
\hline & OAPEN & 11 \\
\hline & Other OA & 34 \\
\hline & SAGE Research Methods & 1 \\
\hline \multicolumn{2}{|l|}{ Subtotal } & 187 \\
\hline \multicolumn{2}{|l|}{ Total } & 2567 \\
\hline
\end{tabular}

she created a column for the total number of uses it received each year during its listed date of publication (Y1), the following year (Y2), and so on through eleven years, reflecting titles from 2006 to 2016. Because there were five years of usage reports and eleven years of titles, some titles had records only for more distant years from publication and some had only records for their first year or few years from publication. As a final step before analysis, the researcher cleaned the data set using OpenRefine to remove inconsistencies in metadata fields with fixed values, including minor variations in capitalization and more substantial variations in naming of individual vendor platforms across different catalog records.

The resulting data set included 2,567 e-books (with duplicate titles from different vendors counted distinctly). Some books had no usage data available either because they were open access titles or because the vendor did not provide usable usage reports. For example, Morgan \& Claypool's Synthesis Lectures e-book series include reports in the COUNTER Journal Report 1 format, which aggregates all titles into a single line of reporting for each series, instead of Book Report 1. Titles from vendors with no available data were removed from the data set for analysis, resulting in a final data set of 2,380 e-books (a reduction of 7.28 percent). Table 2 shows the number of titles for each vendor, distinguishing those vendors included and excluded from final analysis.

The removal showed some impact on overall makeup of the final dataset available for analysis: "Professional" audience level texts shrank by 10.1 percent, twice the

To enable analysis of usage over time, the student computed totals for each half year of usage reports for each title to aggregate fall and spring semester use (with summer split in half between them). She computed total uses by year according to length of time from publication: for each book rate of other audience levels; among genres, "Reports" were almost eliminated, shrinking by 92.5 percent (and thus regrouped with the "Other" category for genre analysis); and "Monographs" also shrank by 10.0 percent. The class ranges that were disproportionately reduced were AZ (17.2 
percent), CD (9.1 percent), Z (11.7 percent), and ZA (18.3 percent).

Descriptive statistics for usage across the different fields captured in the data set were calculated in Excel. Like previous studies, the initial analysis divided titles into those with use and those with no use to minimize conflict between different norms of reporting by vendors and across report types. However, after conferring with the campus data consulting service, this study explored two variations on this idea to attempt to recapture the utility of counts of uses of individual e-book use. First, titles were divided into categories based on those that received zero, one, two to ten, or more than ten uses in a given time period. This method captures extent of use while reducing the importance of specific numbers, although comparison of $\mathrm{BR} 1$ and $\mathrm{BR} 2$ reports remains problematic in this scheme due to the naturally higher numbers of sections downloaded (BR2) versus downloads of entire books (BR1). Second, to resolve this problem, for each vendor included individually in the data set (i.e., not included in "Other"), titles in the top quartile of used titles for each vendor were identified. The data set indicates whether a given title is in the top 25 percent of used titles from that vendor used by patrons for each given period in a given report type. This method enables comparison

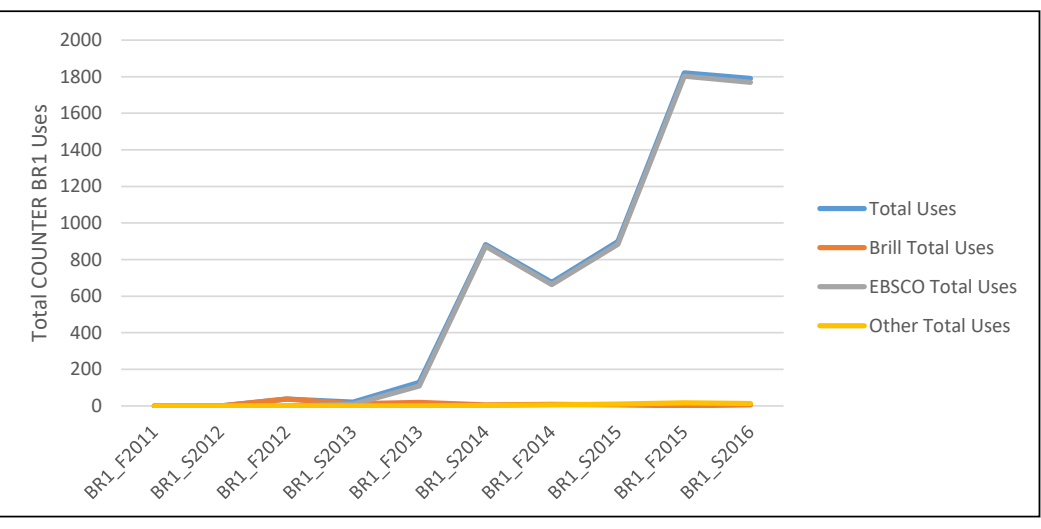

Figure 1. Total Uses by Half Year by Vendor, Book Report 1

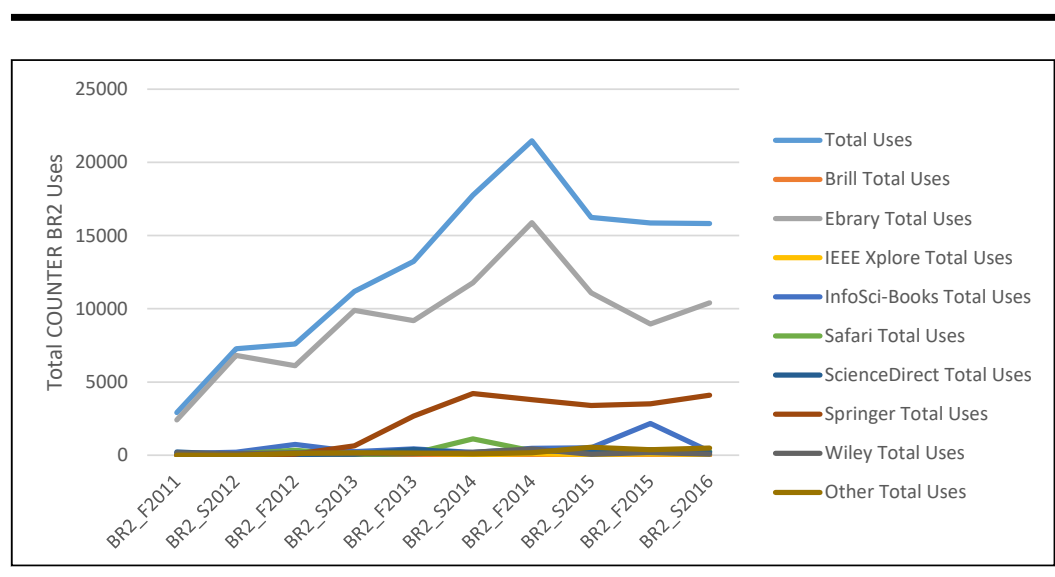

Figure 2. Total Uses by Half Year by Vendor, Book Report 2

of titles from different report types and focuses not on the titles with the greatest raw number of uses but those that are the most used on individual platforms. However, it requires excluding titles from some vendors entirely and some vendors for particular time periods when the library owned such a low number of titles as to be unable to form quartile ranges. For convenience, further explanation of how the top quartile titles were analyzed is provided with discussion of those titles in the "Analysis" section of this paper.

\section{Analysis}

Figures 1 and 2 show the raw totals for use for BR1 and BR2, respectively, across each half-year period by vendor platform. Raw totals from COUNTER reports are of limited use because of reporting variations, especially across report types, and the remainder of this paper generally ignores them or processes them further for analysis; however, these figures demonstrate several factors reflecting local collections practice and use and raise some questions. First, they show a growth of overall use over time followed by a plateau. The plateau in BR2 usage counts tracks closely with a plateau in ebrary usage counts and a rise in BR1 reports for EBSCO: this reflects a shift in title-by-title e-book collections strategy from the ebrary to the EBSCO platform for LIS titles where the two compete against each other and there are no superior platform options (which is true in a large number of cases for LIS). Thus, for more recent years, the new title-by-title selections have mostly occurred in the EBSCO platform. However, EBSCO usage also plateaus at the end of the period and raises the question of whether e-book usage has topped off for a student and faculty population that has grown accustomed to this format. A spike in BR1 for spring 2014 is partly due to a steep increase in the number of EBSCO titles used, but also due to three textbooks used intensely that semester, two of which subsequently dropped off in use; similarly, a spike in BR2 for fall 2014 is due to a handful of titles in ebrary that were either textbooks, handbooks, or essay collections likely to have chapters used in various courses. Second, the difference in scale for BR1 versus BR2 illustrates the impact of downloads by entire book versus downloads by section on usage reports, and why comparison across these 


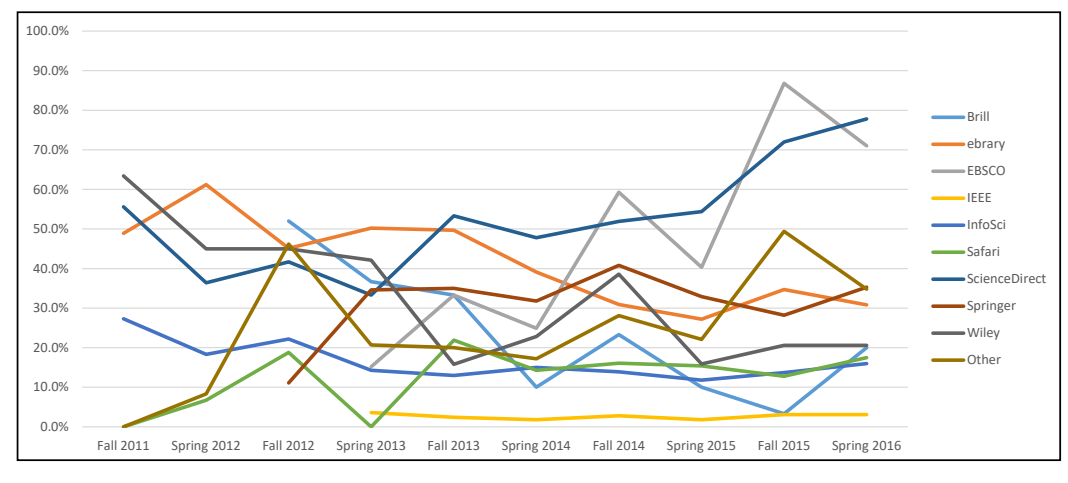

Figure 3. Percent of Titles Used by Half Year, by Vendor

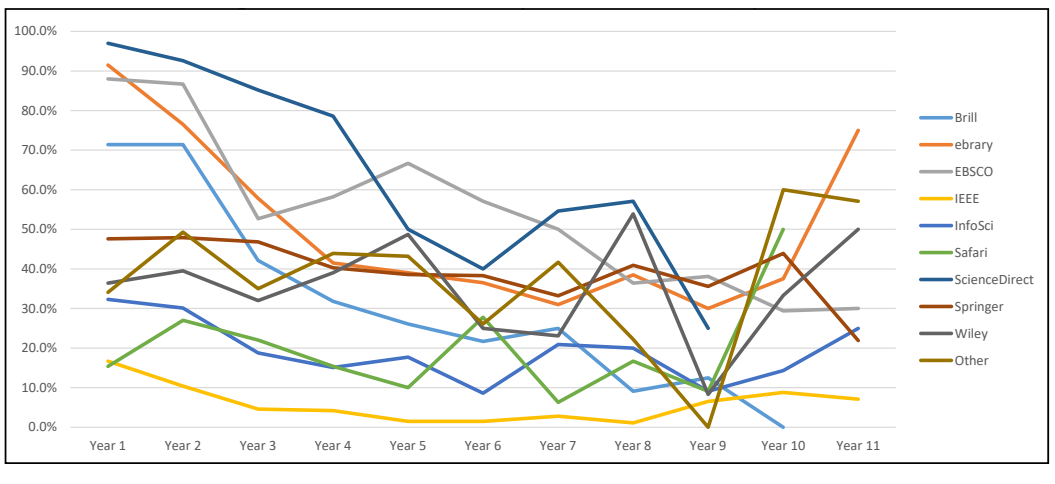

Figure 4. Percent of Titles Used by Year from Publication, by Vendor size and a relatively stable number of users. The exceptions are EBSCO's significant increase in recent years due to the increase in new title-by-title purchases from that platform, and ScienceDirect's rise in recent years, likely tied to Elsevier's acquisition of Chandos, which provides a significant LIS book series. However, another pattern is a greater percentage of titles from most vendors regularly being used in the fall than in the spring. This suggests a usage cycle for e-books tied to the academic year.

Figure 4 shows percentage of titles used in their initial year of publication and in subsequent years. It reveals an overall decline in percentage of titles used as they age. Notably, an extremely high percentage of title-by-title purchases are used in their first two years of publication from the two primary vendors for such purchases in LIS, ebrary, and EBSCO, and, to a lesser extent, with Brill. Titles from one e-book bundle, ScienceDirect, perform especially well in this period (although the number of LIS titles in this collection is much smaller than ebrary or EBSCO, and numbers for ScienceDirect may be inflated due to missing reports for some titles that are difficult to interpret since ScienceDirect provides zerouse titles in their reports). Titles from another report types requires an approach that negates the impact of such variation. In spring 2016, the library owned 500 LIS e-books in EBSCO, 71 percent of which were used in that period, compared to 364 in ebrary, only 31 percent of which were used, yet EBSCO e-book aggregate uses total less than a fifth of ebrary's total. Because the titles in these collections tend to be comparable and EBSCO has the more recent titles, the effect here is reasonably assumed to be a product of different counting mechanisms and book report types despite the fact that the two platforms are extremely similar in terms of user experience and functionality of downloading.

\section{Analysis of Use Versus Non-Use}

For the purpose of reporting the analysis in this section, figures $3-11$ are used to visually communicate trends in use over time. Tables showing the raw counts and percentages underlying these figures may be found in appendix A.

The pattern of usage by vendor semester-by-semester and by time from publication, as shown in figures 3 and 4 , respectively, shows other trends. Figure 3 shows that, as the total number of e-books has grown, the percentage of titles used has remained similar or slightly declined for most publishers. This pattern fits with growing collection e-book bundle, Springer, shows about half of LIS-related titles used in their first year (if the missing ScienceDirect titles are counted as zeros, it also runs at about half of titles used). Looking at the year of publication, the percentage of e-books owned and used in their first year has grown substantially from 46 percent (for 2012 titles) to 79 percent (for 2016 titles). In general, e-books in LIS show surprising staying power, with over 27.6 percent of all titles owned continuing to be used as far as eleven years after publication. This provides a very different picture of LIS e-book use than previous studies and demonstrates little evidence of problems with marketing and awareness of e-books that others have considered as the source low usage statistics in prior studies.

Analysis of particular categories of texts reveal varying degrees of usefulness in breakdown. Figures 5 and 6 show the percentage of titles used over time as broken down by the audience level for the text. Patterns regardless of audience level track closely with one another: significant fluctuation for earlier half year periods for "Other" (Basic and Popular) titles, and for later years from publication date for General Academic and Other titles, likely derive from the small number of overall titles owned in those periods. The most useful finding from this breakdown is that titles with a professional audience do fairly well and continue to be 
used after initial publication at rates as strong or stronger than other titles besides those for a general academic audience. This fact validates the collection of these titles, which is somewhat more common for LIS than other subject areas in the library due to collecting for a professional degree program. However, the longevity of this content is unexpected since it is likely to become outdated faster: books in this category often include those on topics such as implementing particular technologies in libraries, museums, and archives, and newer books quickly replace older ones as technology changes.

Breakdown of use versus non-use for different genres of book, as shown in figures 7 and 8 , reveals steady patterns for most types of texts. Notably, monographs, conference proceedings, and essay collections (either edited collections or collections by one author) demonstrate very similar levels of use not just on a semester-by-semester basis but by year from publication, except as collections begin to outpace monographs in terms of percent of titles used in later years. Monographs do not behave differently from collections by this metric until their slightly lower use in later years. More surprisingly, a larger percentage of textbook titles are used on a semester-by-semester basis and

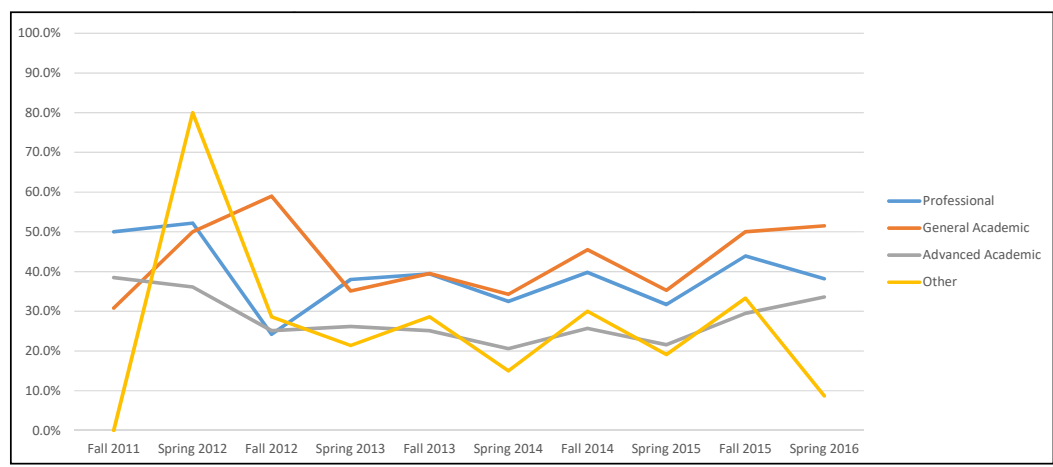

Figure 5. Percent of Titles Used by Half Year, by Audience

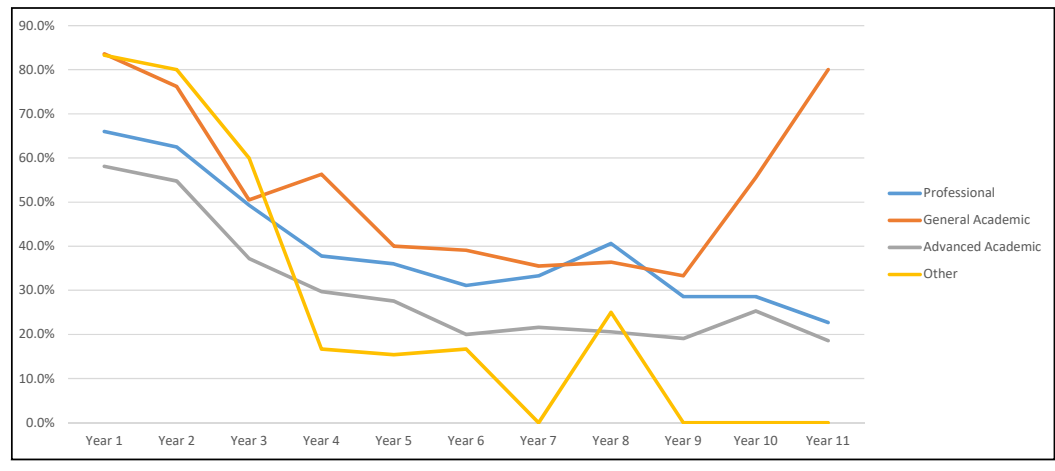

Figure 6. Percent of Titles Used by Year from Publications, by Audience perform well over the medium term in length from publication. Individual textbooks would have expected heavy use, but if textbook use were purely driven by course selection, it would not be likely for a large percentage of all textbooks to be used versus other genres. Handbooks, guides, and technical manuals (HGT) perform similarly to textbooks in the years immediately following publication and then follow the pattern for monographs, collections, and proceedings. Bibliographies also perform very strongly, although a relatively small part of the collection. Even though the LCC's Z class range used for selection of e-books in this study excluded the "bibliographies" subrange, many appeared from other class ranges. These are generally reader's advisory titles, often but not exclusively for young adult readers, rather than research bibliographies. However, when students can acquire such information through licensed tools like NoveList or freely online through sites like Wikipedia or Goodreads, the broad use of these titles is surprising. Other reference titles (dictionaries, biographies, and directories) and encyclopedias perform most strongly; in the case of encyclopedias, this is not surprising, but the other reference types include sources most often considered to be made irrelevant by the internet. Like bibliographies, these perform better than expected.

Breaking down use versus non-use over time by LC class range, as shown in figure 9, demonstrates growth in interest semester-over-semester related to some specific content areas. These include AM (museums), AZ (largely for this collection digital humanities), CD (archives), $\mathrm{K}$ (law, in this collection primarily as related to technological privacy and copyright), $\mathrm{P}$ (literature, in this collection primarily related to history of children's literature and some history of the book and reading), and HM (social sciences studies information). The growth in the percent of titles used in $\mathrm{AM}, \mathrm{AZ}, \mathrm{CD}, \mathrm{K}$, and $\mathrm{P}$ areas are similar in that these are relatively small groups overall, suggesting a demand for greater content in specific areas, but it is not clear if the percent of titles used would remain as high if the number of titles increased substantially. The HM class is a mediumsized subset of texts and reveals increasing demand even within a larger subcollection.

Analysis of use by class range since time of publication, as shown in figure 10, reveals that $\mathrm{T}$ (technology) titles already used at lower rates, receive the least use over time. Titles in the HD range (largely here related to information management) perform on a similar trajectory. The results indicate some possible limitations of using the broadest LC classes to break down disciplinary behavior as has often been done in prior studies. For example, HM titles perform much more strongly semester-by-semester and by length of time from publication than either HC or HD titles: the "H" 


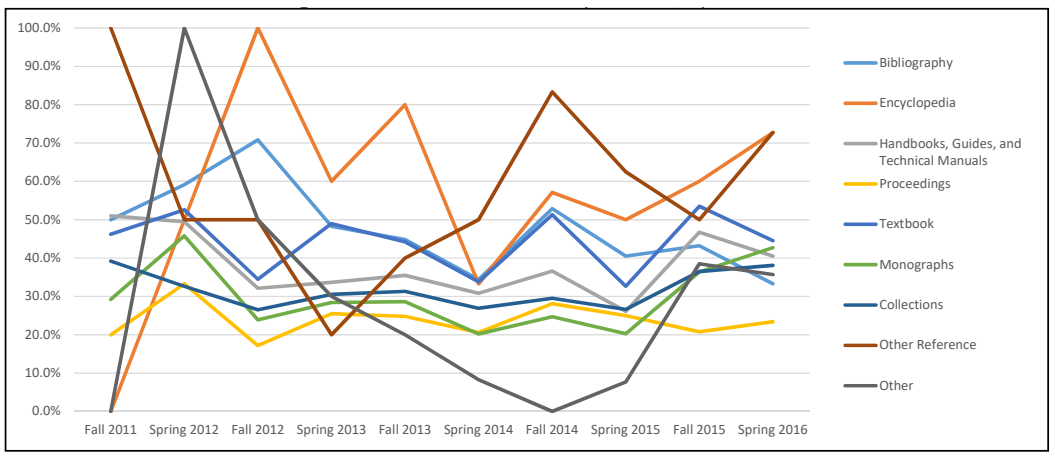

Figure 7. Percent of Titles Used by Half Year, by Genre

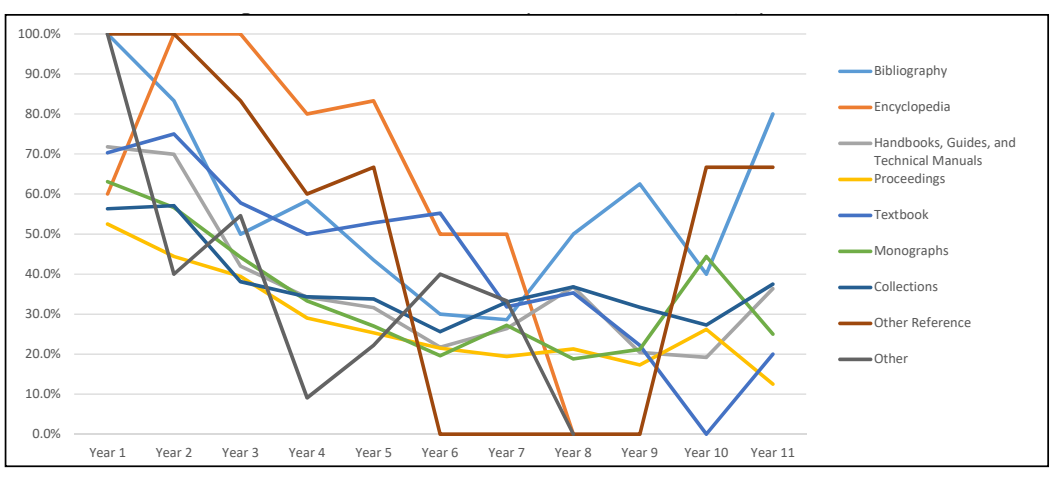

Figure 8. Percent of Titles Used by Year from Publication, by Genre

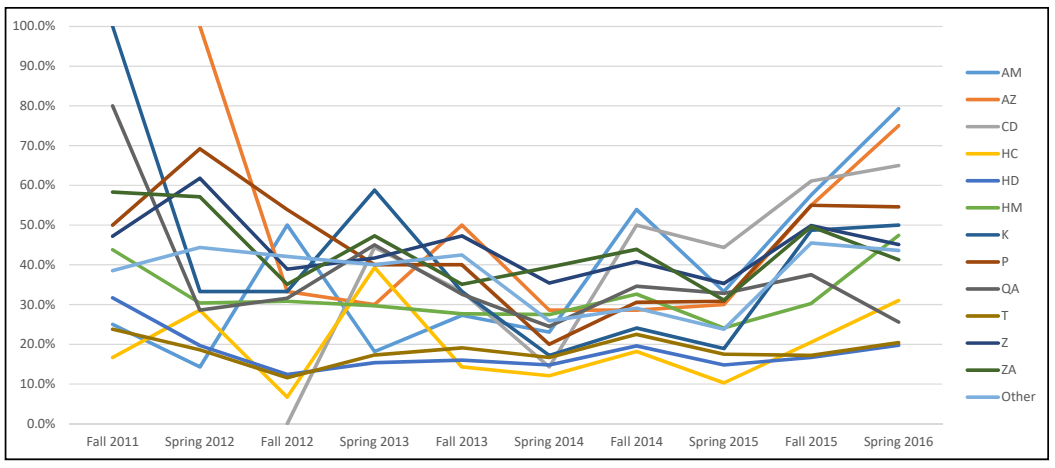

Figure 9. Percent of Titles Used by Half Year, by LC Class Range

class is diverse and includes what are really fairly distinct types of disciplinary production and consumption. The more traditionally identified LIS areas, $\mathrm{Z}$ and $\mathrm{ZA}$, receive different usage, especially in their first year. $\mathrm{Z}$ in particular may merit further breakdown since it includes sub-ranges that are driven more by humanistic methods (such as history of the book and history and practice of publishing) and those that focus on areas related to management and operations of libraries.

Finally, when considering publication year, it is clear that e-book use in general has become much more commonplace among users working in these areas (see figure 11). For titles with a 2012 publication date, 46 percent were used in their first year and 57.1 percent in their second year. For titles with a 2015 publication date, by contrast, 69.9 percent were used in their first year and 72.5 percent in the second year. For 2016 titles, the percent used in their first year grew to 79 percent (with no data available for the second year). It is important to note that the 2016 number is likely low because usage statistics were available only for the first half of the year for this study, greater amounts of use happen in the fall (as noted earlier), and a relatively small number of new titles are acquired in fall verses spring due to collection development patterns.

\section{Analysis by Classification of Level of Use}

Classifying levels of use into bins of zero uses, one use, two to ten uses, and more than ten uses shows some similar patterns with additional nuances and some departures. Due to differences in counting, analysis of BR1 and BR2 must be separated for this analysis. However, because of the relatively small number of publishers using COUNTER BR1, those books are examined here in general and not in the category breakdowns.

Figure 12 shows the overall breakdown of usage classifications over time from publication for BR1 and BR2. A noticeable pattern is that the percentage of titles used only once or those used two to ten times both shrink faster than the percentage of the titles used most frequently (over ten times). This is particularly true for the BR1 titles, although likely made more dramatic by the focus on title-by-title purchasing in EBSCO for the most recent years. This persistence of the most highly used category seems likely related to course adoption of individual chapters or entire books, even if the title is not a textbook.

Figure 13 shows patterns in use over time for different audience levels for publishers using Book Report 2: Professional, General Academic, and Advanced Academic. Advanced Academic titles, the most numerous, closely track the general pattern for BR2 titles. Like the general analysis of use versus non-use, this breakdown shows more longevity of professional titles, particularly in the highest use category, than expected. However, General Academic titles show the most longevity in terms of whether titles are used plus in terms of titles in the top two usage categories. This pattern 
for generalist titles may draw from a relatively small number of titles compared to the other groups, but it also makes intuitive sense for these more accessible titles to receive greater use than more specialized titles. Not visualized here are the "Other" titles, for "Basic" or "Popular" audience levels, which are very small in number but also see nearly all of their use in their first year of publication.

Figure 14 shows patterns in use over time for five genres with a substantial number of titles: Monographs, Collections, Proceedings, Textbooks, and Handbooks, Guides, and Technical Manuals. Notably, while monographs, proceedings, and collections appeared to behave very similarly when looking purely at use versus non-use, collections in particular distinguish themselves from the other two with greater percentages of titles used more than ten times initially and in later years after publication. Beyond those three genres, handbooks, guides, and technical manuals are used even more at the highest level over the long term. Textbooks have the highest percentages over time of titles used over ten times and between two to ten times. This may seem expected, since any textbooks used by courses would receive extensive use, but the overall large percentage used between two to ten times suggests, like the persistence of a large percent of textbooks used overall, that many of these titles are used by students as reference texts outside of particular course contexts.

Figure 15 shows patterns in use over time from publication broken down by LC class ranges for the six ranges with a substantial number of titles: HD, HM, QA, T, Z, and ZA. Class ranges $\mathrm{HD}$ and $\mathrm{T}$ behave most similarly to the overall collection, shrinking most

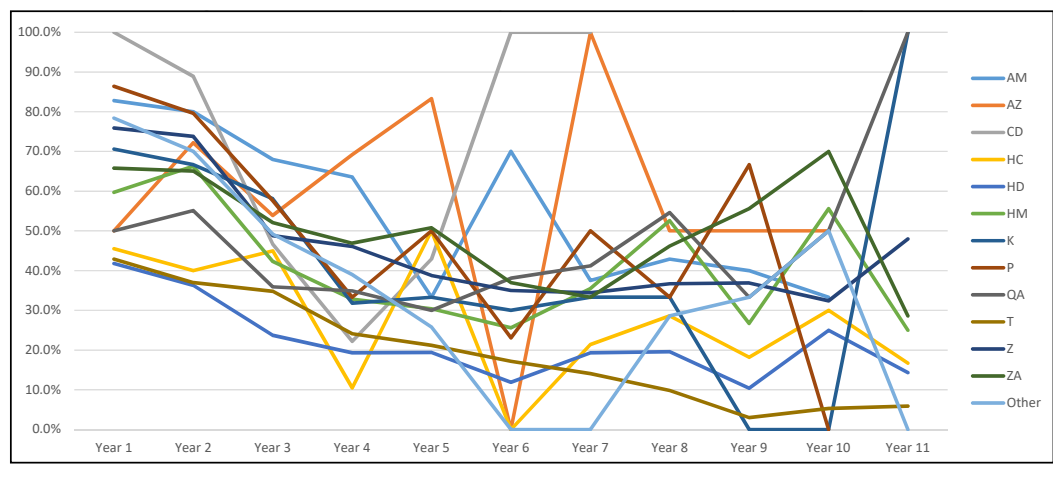

Figure 10. Percent of Titles Used by Year from Publication, by LC Class Range

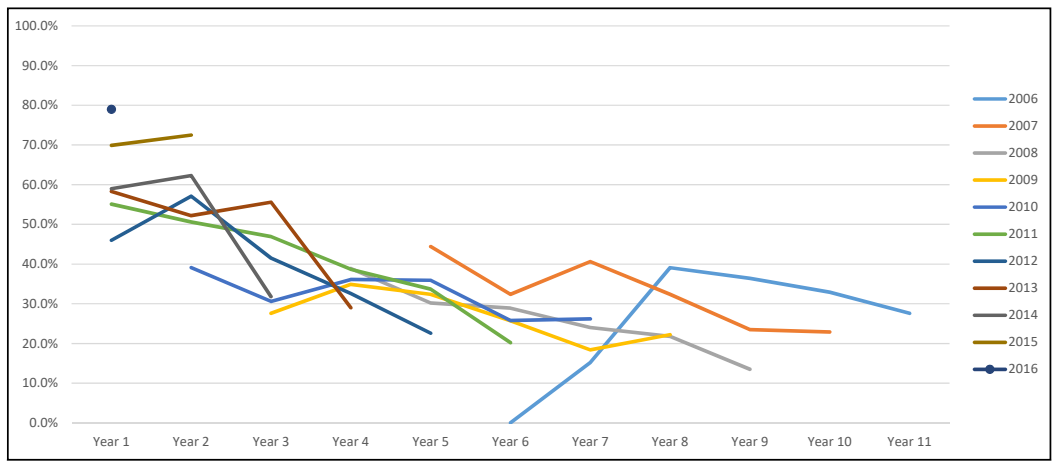

Figure 11. Percent of Titles Used by Year from Publication, by Publication Year

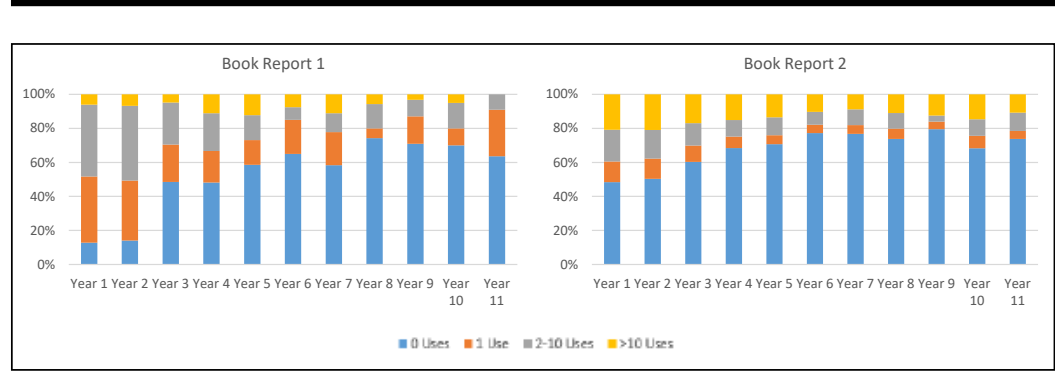

Figure 12. Use Class by Year from Publication, by Book Report Type in overall percentage of titles that are used, although with less overall "high" use at all points from publication than other class ranges. HM titles persist with slightly stronger use and over the medium term the percentage of titles with two to ten uses maintains itself more steadily than the other categories, which might be expected from longer term research use of books in the social sciences (here studies of information in society). However, the strongest areas of use are the core library and information science class ranges $\mathrm{Z}$ and ZA. What is impressive in $\mathrm{Z}$ is that up to 20 percent of these titles are used more than ten times a year over even the medium to long-term. The QA range behaves the most erratically in terms of the percentages of titles being used at high or moderate levels over time, and it is not clear what is driving such variation except perhaps the relatively low number of titles overall combined with irregular course adoptions or spurts in research activity, or both.

\section{Analysis of Top Quartile Titles}

Titles identified as being in the top quartile of used titles for each publisher were analyzed by audience, genre, and class range to determine which categories overperformed as heavily used titles relative to their size in the collection overall. For each category within a particular breakdown, the total number of top-quartile titles was determined, plus the percentage of titles of the total top quartile titles that category represented. The total number of titles in the category 


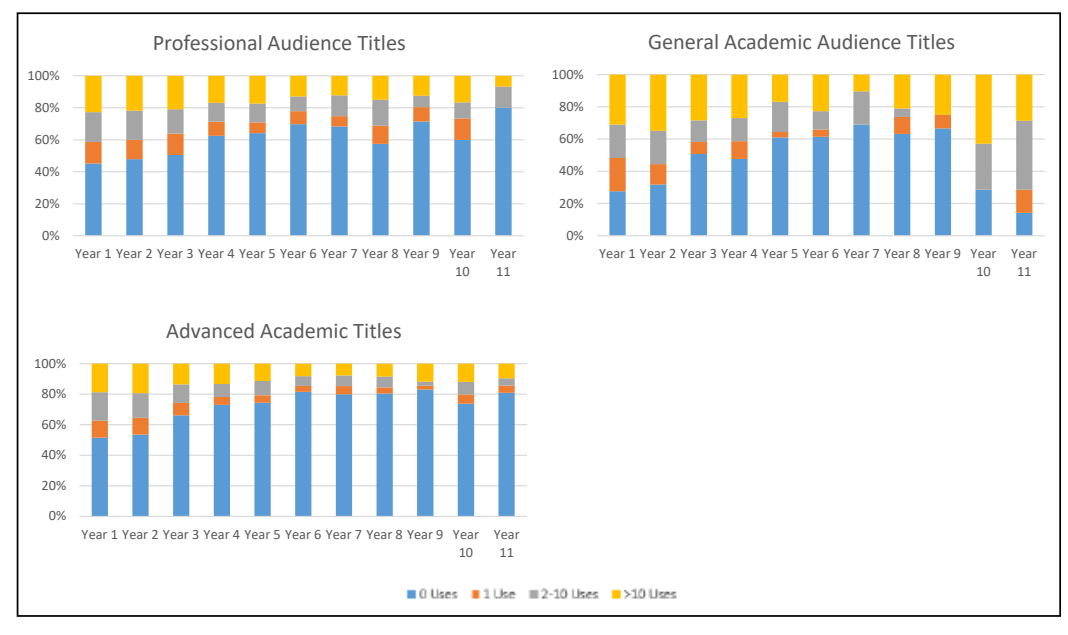

Figure 13. Use Class by Year from Publication, by Audience

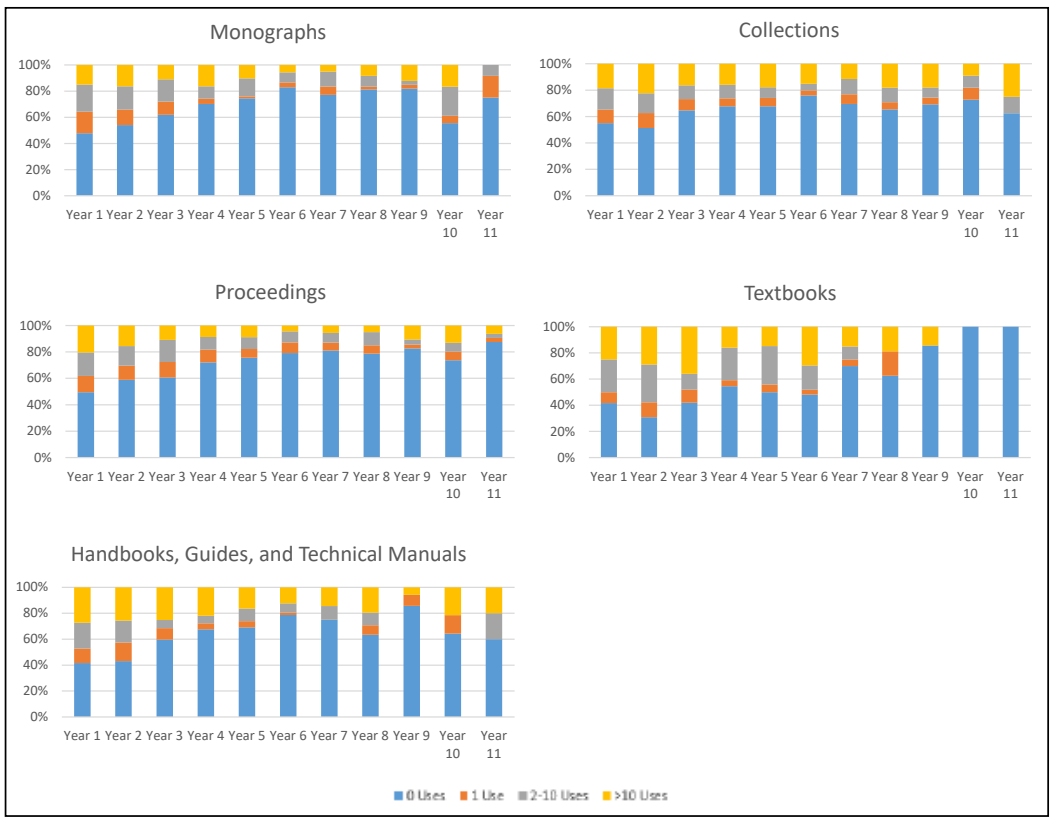

Figure 14. Use Class by Year from Publication, by Genre

overall for the publishers included in this part of the analysis was calculated, with the percentages of titles it represented in the collection overall. Appendix B shows the statistics for these preliminary calculations. Finally, the percentage of titles the category had in the top quartile was divided by the percentage of titles in the collection, creating a relative usage index (table 3). Any values greater than one indicate overrepresentation among the most highly used titles, and any values less than one indicate underrepresentation among the top quartile titles (a zero indicates no titles in the category were in the top quartile in a given year; an "N/A" indicates no titles were owned in the category for that year).
The breakdown by audience shows the strongest performance by general academic books. While they are more likely to show use, titles aimed at a professional audience perform only slightly ahead of their presence in the collection. The exception to this pattern is over the medium term, which again shows greater longevity for at least a set of professional texts than might be expected. Advanced academic texts are less present in the top quartile texts than in the overall collection until later years after a drop-off in use of professional level texts. This rise of more specialized texts (those books with greater use of jargon and a narrower focus) over the long term matches the idea of the "long tail" of use, where, at a certain age, books are most likely to be used by those pursuing advanced research rather than for courses and general reference.

Examining the top quartile texts broken down by genre, Encyclopedias, and Other Reference (Dictionaries, Biographies, Directories) perform especially well in the first four years, although both have a relatively small number of texts overall. The steep drop-off afterwards to a total lack of those reference titles appearing in the top quartile texts appears to reflect that the key texts in the data set are more recent rather than a long-term lack of interest. Textbooks show a longer life of strong use than might be expected given the frequency with which publishers release new editions of these texts. Bibliography mostly performs very well, showing not just breadth of demand but strength of demand for these titles over a long period. Monographs and proceedings perform the least well, and monographs only perform ahead of their presence in the collection in the latest years of the collected data, whereas collections perform moderately well.

Broken down by class ranges, the top quartile titles show some flux in areas of strength from year to year. However, the classes T (technology), HC (economics of information), and HD (knowledge management and information management) do not perform well until the end of the period of the data collection, at which point a number of classes have no titles in the data set to compete. The classes AM (museums) and CD (archives) perform particularly well early on, and then more moderately well. The classes AZ (digital humanities) and P (literature) perform well in the medium term. Titles in the HM class (information in society) appear to grow in strength in representation in the top quartile. The core library-related classes, $\mathrm{Z}$ and to a 
lesser extent ZA, perform well over the entire lifecycle. Generally, the humanistic and social science related areas-AM, AZ, CD, HM, K, $\mathrm{P}$ - show strength across several years, showing not just uses of a large percent of these titles but also a depth of use for them as well.

\section{Discussion}

This study shows a much stronger performance of LIS e-book titles than has been noted in prior studies, which show them performing somewhere between slightly ahead of average or poorly compared to other areas of collections. About 60 percent of LIS titles are used in each of their first and second year of publication, and that amount increases substantially year-byyear, with almost 80 percent of new 2016 titles used in their first year. Over 27 percent are still used eleven years after publication, and 20 per-

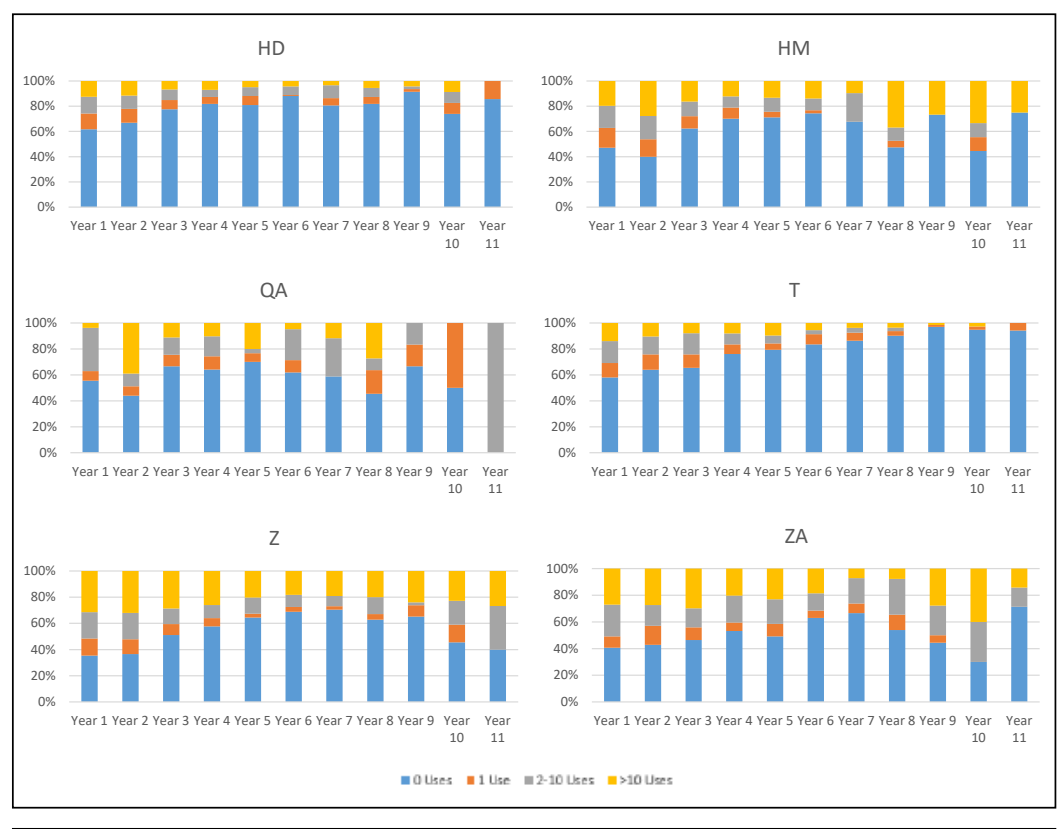

Figure 15. Use Class by Year from Publication, Library of Congress Class Range cent of $\mathrm{Z}$ titles are used more than ten times a year in the last years of the data set-a greater proportion of $\mathrm{Z}$ titles than were used at all in the early study by Sprague and Hunter. Greater LIS e-book use than other studies may be due to the local institutional context: a large iSchool with a major program in library and information science means significantly more course uptake and research uses, and requirements for research and publication for library faculty in addition to iSchool faculty may make for more active librarian book users. Most of the areas outside of $\mathrm{Z}$ and ZA are part of LIS collections but in practice include research areas split among departments that may have more varied uptake of e-books as opposed to the longer term of collection of e-books in LIS that may have created an earlier shift. However, the performance of humanistic and humanistic social science areas in this study (AM, AZ, CD, HM, K, and $\mathrm{P}$ ) suggest that certain fields in these disciplines are more likely to adopt e-books than has been apparent in some other studies and may even be fairly underserved either in purchasing patterns or content availability.

Regarding audience breakdown, professional-level titles performed better than anticipated over the medium term, although not as strongly as general academic titles. Advanced academic titles were the most common audience level but performed the weakest year-by-year, but this is expected for titles that would have more targeted research audiences, and their stronger presence in the top quartile titles in the latest years of the study indicate the stronger research-focused use of older collections as opposed to teaching and reference uses.

The study shows several differences among the performance of various genres, with encyclopedias and other

reference texts not surprisingly doing well both in terms of numbers of books used and the extent to which they are used, although they are a relatively small number compared to other groups. More interesting is the strong showing among bibliographies, which also over-perform among the top quartile of used books in many years post-publication. One question arising from this study is whether the strong performance of bibliographies is true of LIS specifically (due to the prevalence of reader's advisory bibliographies and their likely use for course projects) or true more broadly. Many individual textbooks are used extensively, but this study also shows broad use of a large number of textbooks and use in moderate amounts of two to ten uses in a year which suggests these volumes are used for more than just assigned course readings. This study shows greater differences in performance by monographs and collections than that shown previously by Freeman and Saunders who described slightly more pages and passages read in collections than monographs. LIS collections and monographs show similar proportions of titles with access in early years followed by heavier use of collections, but moreover, collections are over-represented in the top quartile of used titles for almost the entirety of time from publication studied here, where monographs are under-represented until ten years after publication.

The fact that LIS cuts across many different areas of LCC allows some reflection on relevance of this study to further work in the study of e-books since class ranges are typically used for disciplinary breakdowns in other research. The difference of the HM subclass range from HC and HD (both more related to economics and business) in this study, 
Table 3: Top Quartile Relative Usage Index by Category*

\begin{tabular}{|c|c|c|c|c|c|c|c|c|c|c|c|}
\hline Category & Year 1 & Year 2 & Year 3 & Year 4 & Year 5 & Year 6 & Year 7 & Year 8 & Year 9 & Year 10 & $\underline{\text { Year } 11}$ \\
\hline \multicolumn{12}{|l|}{$\overline{\text { Audience }}$} \\
\hline Professional & 1.0271 & 1.0017 & 1.1480 & 1.0994 & 1.3563 & 1.3603 & 1.1953 & 0.7532 & 0.8248 & 0.7500 & 0.0000 \\
\hline General Academic & 1.6151 & 1.8539 & 1.2568 & 1.6233 & 1.7087 & 1.6172 & 1.6300 & 1.0043 & 1.6496 & 3.0000 & 4.0000 \\
\hline Advanced Academic & 0.9230 & 0.8974 & 0.8867 & 0.9029 & 0.7810 & 0.8068 & 0.8947 & 1.2256 & 1.0521 & 0.9800 & 1.2000 \\
\hline Other & 0.9184 & 0.6393 & 1.3857 & 0.0000 & 0.0000 & 0.0000 & 0.0000 & 0.0000 & 0.0000 & 0.0000 & 0.0000 \\
\hline \multicolumn{12}{|l|}{ Genre } \\
\hline Bibliography & 1.0019 & 1.2294 & 0.7506 & 2.3087 & 1.3105 & 2.0485 & 1.9405 & 0.0000 & 2.1209 & 2.1000 & 2.6667 \\
\hline Encyclopedia & 3.3063 & 3.6530 & 6.7553 & 5.7717 & 0.0000 & 0.0000 & 0.0000 & N/A & N/A & N/A & $\mathrm{N} / \mathrm{A}$ \\
\hline \multicolumn{12}{|l|}{ Handbooks, Guides, } \\
\hline and Technical Manuals & 1.2644 & 1.0559 & 1.2661 & 1.2051 & 1.3550 & 0.6510 & 1.2511 & 0.8070 & 1.0239 & 0.8077 & 0.0000 \\
\hline Proceedings & 0.8793 & 0.7444 & 0.7642 & 0.8750 & 0.9177 & 0.6905 & 0.6318 & 1.0184 & 0.8733 & 0.7000 & 0.4211 \\
\hline Textbooks & 1.2142 & 1.7047 & 2.0886 & 1.6161 & 1.0671 & 2.7435 & 1.5093 & 1.1298 & 0.0000 & 0.0000 & 0.0000 \\
\hline Other Reference & 1.8368 & 2.1309 & 3.0023 & 2.3087 & 0.0000 & 0.0000 & 0.0000 & 0.0000 & 0.0000 & 0.0000 & N/A \\
\hline Other & 2.7552 & 0.0000 & 1.1259 & 0.0000 & 0.0000 & 3.0727 & 0.0000 & 0.0000 & N/A & N/A & $\mathrm{N} / \mathrm{A}$ \\
\hline Monographs & 0.7749 & 0.8054 & 0.5774 & 0.7782 & 0.7661 & 0.6828 & 0.7056 & 0.5317 & 0.6186 & 2.1000 & 1.7778 \\
\hline Collections & 0.8644 & 1.0708 & 1.0149 & 0.8912 & 1.0477 & 1.5364 & 1.7912 & 1.6601 & 1.8558 & 1.4000 & 2.6667 \\
\hline \multicolumn{12}{|l|}{ Class } \\
\hline AM & 2.1648 & 1.3699 & 0.7832 & 1.1543 & 1.3833 & 0.0000 & 0.0000 & 1.5064 & 4.9487 & 0.0000 & $\mathrm{~N} / \mathrm{A}$ \\
\hline$A Z$ & 0.6123 & 1.2785 & 1.6376 & 1.0494 & 0.0000 & N/A & 6.7917 & N/A & 0.0000 & 10.5000 & N/A \\
\hline CD & 2.5047 & 1.0654 & 1.2009 & 0.0000 & 0.0000 & 0.0000 & 0.0000 & $\mathrm{~N} / \mathrm{A}$ & N/A & N/A & $\mathrm{N} / \mathrm{A}$ \\
\hline $\mathrm{HC}$ & 0.5009 & 0.5114 & 0.4504 & 0.0000 & 0.0000 & 0.0000 & 0.9702 & 0.0000 & 3.7115 & 1.3125 & 0.0000 \\
\hline HD & 0.6209 & 0.5047 & 0.4895 & 0.4036 & 0.3532 & 0.2604 & 0.3396 & 0.4017 & 0.5499 & 1.0500 & 1.0000 \\
\hline HM & 0.9184 & 1.3699 & 1.5441 & 0.7696 & 1.1066 & 1.4632 & 1.8736 & 3.3894 & 1.2372 & 1.5000 & 2.6667 \\
\hline K & 1.8368 & 0.7376 & 1.2282 & 0.0000 & 3.1123 & 0.0000 & 4.5278 & 0.0000 & 0.0000 & 0.0000 & $\mathrm{~N} / \mathrm{A}$ \\
\hline $\mathbf{P}$ & 1.1021 & 1.4752 & 1.5529 & 1.8470 & 0.6552 & 0.0000 & 0.0000 & 0.0000 & 0.0000 & 0.0000 & N/A \\
\hline QA & 0.3674 & 1.3318 & 0.7206 & 0.8446 & 2.1464 & 0.7682 & 1.8111 & 3.8736 & 0.0000 & 0.0000 & $\mathrm{~N} / \mathrm{A}$ \\
\hline$T$ & 0.4984 & 0.4319 & 0.5382 & 0.6113 & 0.6061 & 0.7717 & 0.4299 & 0.4108 & 0.0000 & 0.0000 & 1.0000 \\
\hline z & 1.3047 & 1.4102 & 1.4550 & 1.7514 & 1.4743 & 1.7071 & 1.9718 & 1.1298 & 1.7466 & 1.3125 & 0.8000 \\
\hline$Z A$ & 0.9058 & 1.1623 & 1.4685 & 1.3151 & 1.5809 & 2.2761 & 0.6626 & 0.9038 & 1.8558 & 2.1000 & 1.6000 \\
\hline Other & 1.3177 & 0.7991 & 0.6551 & 1.1839 & 1.7785 & 0.0000 & 0.0000 & 1.5064 & 0.0000 & 5.2500 & 0.0000 \\
\hline
\end{tabular}

*Index scores derived by dividing the percentage of titles within a category falling into the top quartile of used books for their respective publishers by the percentage of that category represented in the collection overall. For preliminary percentages, see Appendix B, tables B1 and B2. N/A indicates that insufficient titles existed to form quartiles for the category in a particular year. Darker blue cells indicate categories that were most over-represented among top-quartile titles in a given year. Darker yellow tiles indicate categories that were most under-represented in the top-quartile titles.

for example, shows that the "social sciences" class may not behave uniformly, and this could apply to other ranges. The most nuanced breakdown of disciplines in LC ranges in a larger cross-collection study of e-book use to date has been Knowlton's, which provides for thirty-two disciplinary areas with LC class ranges broken out and recombined accordingly. ${ }^{21}$ The primary distinction lacking in his schema that would be useful from the perspective of the present study would be to separate out the part of the $\mathrm{Z}$ class range related to bibliographies for other areas rather than conflating it with librarianship. Nonetheless, as a caveat to this study it is worth remembering that these disciplinary breakdowns are not complete: history in particular can be found spread out well beyond the primary history class ranges.

Finally, it is worth noting that the use of newly published titles in this study shows the percentage of titles accessed in their first two years rising dramatically. It may be that this pattern stabilizes and plateaus before reaching 100 percent, but it raises the point that as e-book use becomes common among a variety of disciplines and levels off, examinations of usage statistics limited to use versus non-use will likely lose their ability to provide insight into user behavior. This lost utility will result because e-book use will be so ubiquitous that almost every title will be used, or because there will no longer be any significant changes in disciplinary comparisons, or both. Beyond understanding what disciplines are adopting e-books, it may become more useful to examine more popular topical areas or categories of text in particular fields. Use versus nonuse is the easiest way to make use of the limited nature of usage statistics, but further work will need to provide novel ways of using these statistics. It would help improve this situation dramatically if COUNTER would push for more consistency in implementation of usage statistics standards across vendors.

\section{Conclusion}

This study shows robust local adoption of e-books in library and information science, both in terms of the percentage of 
titles accessed and the longevity and depth of use of titles. E-books appear to make for a larger "long tail" of academic use plus their greater use in early years. There are stark differences and surprises among genres and class ranges. Among genres, textbooks show breadth and depth of use that imply broad use outside of the relatively small number adopted for courses. Bibliography also performs well, which may be particular to library and information science due to use of reader's advisory titles in coursework and deserves further investigation. The strong performance of humanistic class ranges suggests the areas explored in this study may be underserved presently.

Introducing additional categories of analysis beyond class is one way that this study sought to expand what is possible with e-books. Further work that may be useful would be to examine intersections of factors, particularly the intersection of genre with class ranges, especially in areas of relatively low e-book use as in the HC, HD, and T classes here, where identifying any patterns across the titles that are used versus those that are not would be helpful.

Additional investigation of how to make use of COUNTER usage data beyond the used versus unused distinction is needed as e-books become more common in academic libraries and questions about collections use shift away from the question of whether individual disciplines are adopting e-books. More uniform implementation of the COUNTER standard would be useful, as would more transparency from publishers as to their individual implementations.

\section{References}

1. Angela Conyers et al., "E-Book Usage: Counting the Challenges and Opportunities," Insights the UKSG Journal 30, no. 2 (2017): 23-30, 24, https://doi.org/10.1629/uksg.370.

2. Tao Zhang, Xi Niu, and Marlen Promann, "Assessing the User Experience of E-Books in Academic Libraries," College b Research Libraries 78, no. 5 (2017): 578-601, https://doi. org/10.5860/crl.78.5.578.

3. Robert Slater, "E-Books or Print Books, 'Big Deals' or Local Selections - What Gets More Use?," Library Collections, Acquisitions, \& Technical Services 33, no. 1 (2009): 31-41, https://doi.org/10.1016/j.lcats.2009.03.002; Steven A. Knowlton, "A Two-Step Model for Assessing Relative Interest in E-Books Compared to Print," College \& Research Libraries 77, no. 1 (2016): 20-33, https://doi.org/10.5860/crl.77.1.20; Jan C. Horner, "E-Preferred Approval Books at the University of Manitoba: A Comparison of Print and E-book Usage," Evidence Based Library \& Information Practice 12, no. 2 (2017): 90-105, https://doi.org/10.18438/B8BT04.

4. TinaChrzastowski, "AssessingtheValue of Ebooksto Academic Libraries and Users," in Proceedings of the 9th Northumbria International Conference on Performance Measurement in Libraries and Information Services (York, England: University of York, 2012), 53-61, accessed January 5, 2018, http://www.york.ac.uk/about/departments/support-andadmin/information-services/performance/northumbriaconference/9th-conference/proceedings.

5. Jeff Staiger, "How E-Books Are Used: A Literature Review of the E-book Studies Conducted from 2006 to 2011," Reference \& User Services Quarterly 51, no. 4 (2012): 355-65.

6. Zhang, Niu, and Promann, "Assessing the User Experience of E-Books in Academic Libraries."

7. Tina E. Chrzastowski and Lynn N. Wiley, "E-Book Use and Value in the Humanities," Library Resources \& Technical Services 59, no. 4 (2015): 172-86, https://dx.doi.org/10.5860/ lrts.59n4.172.
8. Pervaiz Ahmad, Mark Brogan, and Michael N. Johnstone, "The E-Book Power User in Academic and Research Libraries: Deep Log Analysis and User Customisation," Australian Academic \& Research Libraries 45, no. 1 (2014): 35-47.

9. JISC National E-Books Observatory Project, "Scholarly E-Books Usage and Information Seeking Behaviour: A Deep Log Analysis of MyiLibrary, CIBER, Final Report, November 2009," http://observatory.jisce-books.org/reports/ scholarly-e-books-usage-and-information-seeking-behaviour-a-deep-log-analysis-of-myilibrary/.

10. Umut Al, İrem Soydal, and Yaşar Tonta, "Analysis of E-Book Use: The Case of Ebrary," in Publishing in the Networked World: Transforming the Nature of Communication, 14th International Conference on Electronic Publishing (Helsinki, Finland: Hanken School of Economics, 2010), 315-29, https://elpub.architexturez.net/system/files/ pdf/122_elpub2010.content.pdf. The interest in the use of electronic media in scholarly communication is growing. Nowadays, libraries reserve much larger budgets for electronic information sources as users tend to get access to the full-texts of journal articles and books online. The effective management of library collections is only possible through studies identifying user needs as well as studies of usage analysis showing how much of what is being used in these collections. Although e-books are a significant part of library collections, studies on e-book use are scarce. In this paper, we have analyzed about half a million use data of ebrary e-book database by the users of Hacettepe University Libraries within a four-year period (2006-2009

11. Ahmad, Brogan, and Johnstone, "The E-Book Power User in Academic and Research Libraries."

12. Michael Levine-Clark, "E-Book Usage on a Global Scale: Patterns, Trends and Opportunities," Insights the UKSG Journal 28, no. 2 (2015): 39-48, https://doi.org/10.1629/uksg.240. 
13. Knowlton, "A Two-Step Model."

14. Julie Linden, Angela Sidman, and Sarah Tudesco, "Ebrary on the Radar," in Creating Sustainable Community: The Proceedings of the ACRL 2015 Conference (Chicago, Illinois: Association of College and Research Libraries, 2015), 225-35, http://www.ala.org/acrl/sites/ala.org.acrl/files/content/conferences/confsandpreconfs/2015/Linden_Sidman_ Tudesco.pdf; Knowlton, "A Two-Step Model."

15. Nancy Sprague and Ben Hunter, "Assessing E-Books: Taking a Closer Look at e-Book Statistics," Library Collections, Acquisitions, \& Technical Services 32, no. 3-4 (2008): 150-57, https://doi.org/10.1016/j.lcats.2008.12.005.

16. Antje Mays, "Deep Dive: Differentiated E-book Usage Between Collection Types Across Disciplines," Against the Grain 29, no. 1 (2017): 76-81.

17. RobertS. Freeman andE. StewartSaunders, "E-BookReading
Practices in Different Subject Areas: An Exploratory Log Analysis," in Academic E-Books: Publishers, Libraries, and Users, ed. Suzanne M. Ward, Robert S. Freeman, and Judith M. Nixon (West Lafayette: Purdue University Press, 2016), 133-46.

18. Horner, "E-Preferred Approval Books."

19. Slater, "E-Books or Print Books, 'Big Deals' or Local Selections"; Alain R. Lamothe, "Comparing Usage between Selective and Bundled E-monograph Purchases," Collection Building 32, no. 3 (2013): 116-21, https://doi.org/10.1108/ CB-03-2013-006.

20. Molly Olney-Zide and Laura Eiford, "Confessions of a Late Bloomer: Use and Acceptance of an E-Books Program in an Undergraduate Library," Serials Librarian 68, no. 1-4 (2015): 307-17.

21. Knowlton, "A Two-Step Model."

\section{Appendix A}

This appendix includes tables of summary descriptive statistics underlying figures 3-11 in the text. They show trends over time by calendar half year (e.g., January-June 2015) or by year from publication of titles (with Year 1 as the year of publication).

\begin{tabular}{|c|c|c|c|c|c|c|c|c|c|c|}
\hline Vendor & Fall 2011 & Spring 2012 & Fall 2012 & Spring 2013 & Fall 2013 & Spring 2014 & Fall 2014 & Spring 2015 & Fall 2015 & Spring 2016 \\
\hline Brill & N/A & N/A & $52.0 \%(13 / 25)$ & $36.7 \%(11 / 30)$ & $33.3 \%(10 / 30)$ & $10 \%(3 / 30)$ & $23.3 \%(7 / 30)$ & $10.0 \%(3 / 30)$ & $3.3 \%(1 / 30)$ & $20.0 \%(6 / 30)$ \\
\hline ebrary & $48.9 \%(46 / 94)$ & $61.2 \%(112 / 183)$ & $45.1 \%(83 / 184)$ & $50.2 \%(154 / 307)$ & $49.7 \%(154 / 310)$ & $39.1 \%(129 / 330)$ & $30.9 \%(101 / 327)$ & $27.2 \%(93 / 342)$ & $34.7 \%(119 / 343)$ & $30.8 \%(112 / 364)$ \\
\hline EBSCO & N/A & N/A & N/A & $15.2 \%(5 / 33)$ & $33.3 \%(11 / 33)$ & $24.9 \%(43 / 173)$ & $59.3 \%(108 / 182)$ & $40.3 \%(124 / 308)$ & $86.8 \%(275 / 317)$ & $71.0 \%(355 / 500)$ \\
\hline IEEE & N/A & N/A & N/A & $3.6 \%(6 / 169)$ & $2.4 \%(4 / 169)$ & $1.8 \%(4 / 214)$ & $2.8 \%(6 / 218)$ & $1.8 \%(4 / 226)$ & $3.1 \%(7 / 226)$ & $3.1 \%(7 / 226)$ \\
\hline InfoSci & $27.3 \%(15 / 55)$ & $18.3 \%(19 / 104)$ & $22.2 \%(24 / 108)$ & $14.3 \%(22 / 154)$ & $13.0 \%(20 / 154)$ & $15.0 \%(29 / 193)$ & $13.9 \%(27 / 194)$ & $11.8 \%(25 / 212)$ & $13.7 \%(29 / 212)$ & $16.0 \%(36 / 225)$ \\
\hline Safari & $0.0 \%(0 / 9)$ & $6.7 \%(1 / 15)$ & $18.8 \%(3 / 16)$ & $0.0 \%(0 / 29)$ & $21.9 \%(7 / 32)$ & $14.3 \%(8 / 56)$ & $16.1 \%(9 / 56)$ & $15.4 \%(12 / 78)$ & $12.8 \%(10 / 78)$ & $17.5 \%(20 / 114)$ \\
\hline ScienceDirect & $55.6 \%(5 / 9)$ & $36.4 \%(4 / 11)$ & $41.7 \%(5 / 12)$ & $33.3 \%(5 / 15)$ & $53.3 \%(8 / 15)$ & $47.8 \%(11 / 23)$ & $51.9 \%(14 / 27)$ & $54.4 \%(25 / 46)$ & $72.0 \%(36 / 50)$ & $77.8 \%(28 / 36)$ \\
\hline Springer & $\mathrm{N} / \mathrm{A}$ & N/A & $11.1 \%(29 / 261)$ & $34.6 \%(140 / 405)$ & $35.0 \%(144 / 411)$ & $31.8 \%(156 / 491)$ & $40.8 \%(202 / 495)$ & $32.9 \%(186 / 565)$ & $28.2 \%(160 / 568)$ & $35.3 \%(213 / 604)$ \\
\hline Wiley & $63.4 \%(7 / 11)$ & $45.0 \%(9 / 20)$ & $45.0 \%(9 / 20)$ & $42.1 \%(16 / 38)$ & $15.8 \%(6 / 38)$ & $22.8 \%(13 / 57)$ & $38.6 \%(22 / 57)$ & $15.9 \%(10 / 63)$ & $20.6 \%(13 / 63)$ & $20.6 \%(22 / 107)$ \\
\hline Other & $0.0 \%(0 / 1)$ & $8.3 \%(1 / 12)$ & $46.2 \%(6 / 13)$ & $20.7 \%(6 / 29)$ & $20.0 \%(6 / 30)$ & $17.2 \%(11 / 64)$ & $28.1 \%(18 / 64)$ & $22.1 \%(19 / 86)$ & $49.4 \%(43 / 87)$ & $34.8 \%(40 / 115)$ \\
\hline
\end{tabular}

\begin{tabular}{|c|c|c|c|c|c|c|c|c|c|c|c|}
\hline Vendor & Year 1 & Year 2 & Year 3 & Year 4 & Year 5 & Year 6 & Year 7 & Year 8 & Year 9 & Year 10 & Year 11 \\
\hline Brill & $71.4 \%(5 / 7)$ & $71.4 \%(10 / 14)$ & $42.1 \%(8 / 19)$ & $31.8 \%(7 / 22)$ & $26.1 \%(6 / 23)$ & $21.7 \%(5 / 23)$ & $25.0 \%(4 / 16)$ & $9.1 \%(1 / 11)$ & $12.5 \%(1 / 8)$ & $0.0 \%(0 / 2)$ & N/A \\
\hline ebrary & $91.5 \%(151 / 165)$ & $76.5 \%(221 / 289)$ & $57.8 \%(177 / 306)$ & $41.5 \%(126 / 304)$ & $39.0 \%(94 / 241)$ & $36.5 \%(44 / 166)$ & $31.0 \%(26 / 84)$ & $38.5 \%(15 / 39)$ & $30.0 \%(6 / 20)$ & $37.5 \%(3 / 8)$ & $75.0 \%(3 / 4)$ \\
\hline EBSCO & $88.0 \%(278 / 316)$ & $86.7 \%(301 / 347)$ & $52.7 \%(98 / 186)$ & $58.2 \%(32 / 55)$ & $66.7 \%(10 / 15)$ & $57.1 \%(8 / 14)$ & $50.0 \%(9 / 18)$ & $36.4 \%(8 / 22)$ & $38.1 \%(8 / 21)$ & $29.4 \%(5 / 17)$ & $30.0 \%(3 / 10)$ \\
\hline IEEE & $16.7 \%(1 / 6)$ & $10.4 \%(5 / 48)$ & $4.6 \%(4 / 88)$ & $4.2 \%(5 / 118)$ & $1.5 \%(2 / 134)$ & $1.5 \%(2 / 133)$ & $2.8 \%(3 / 107)$ & $1.1 \%(1 / 95)$ & $6.5 \%(4 / 62)$ & $8.8 \%(3 / 34)$ & $7.1 \%(1 / 14)$ \\
\hline Infosci & $32.3 \%(51 / 158)$ & $30.1 \%(59 / 193)$ & $18.8 \%(34 / 181)$ & $15.1 \%(22 / 146)$ & $17.7 \%(18 / 102)$ & $8.6 \%(7 / 81)$ & $20.9 \%(9 / 43)$ & $20.0 \%(3 / 15)$ & $9.1 \%(1 / 11)$ & $14.3 \%(1 / 7)$ & $25.0 \%(1 / 4)$ \\
\hline Safari & $15.4 \%(8 / 52)$ & $27.0 \%(17 / 63)$ & $22.0 \%(13 / 59)$ & $15.4 \%(6 / 39)$ & $10.0 \%(3 / 30)$ & $27.8 \%(5 / 18)$ & $6.3 \%(1 / 16)$ & $16.7 \%(2 / 12)$ & $9.1 \%(1 / 11)$ & $50.0 \%(2 / 4)$ & N/A \\
\hline ScienceDirect & $97.0 \%(32 / 33)$ & $92.6 \%(25 / 27)$ & $85.2 \%(23 / 27)$ & $78.6 \%(11 / 14)$ & $50.0 \%(5 / 10)$ & $40.0 \%(4 / 10)$ & $54.6 \%(6 / 11)$ & $57.1 \%(4 / 7)$ & $25.0 \%(1 / 4)$ & N/A & $0.0 \%(0 / 1)$ \\
\hline Springer & $47.6 \%(140 / 294)$ & $47.9 \%(180 / 376)$ & $46.8 \%(170 / 363)$ & $40.3 \%(130 / 323)$ & $38.6 \%(103 / 267)$ & $38.3 \%(85 / 222)$ & $33.2 \%(61 / 184)$ & $40.9 \%(52 / 127)$ & $35.6 \%(32 / 90)$ & $43.9 \%(25 / 57)$ & $21.9 \%(7 / 32)$ \\
\hline Wiley & $36.4 \%(12 / 33)$ & $39.5 \%(17 / 43)$ & $32.0 \%(16 / 50)$ & $39.0 \%(16 / 41)$ & $48.7 \%(18 / 37)$ & $25.0 \%(8 / 32)$ & $23.1 \%(6 / 26)$ & $53.9 \%(7 / 13)$ & $8.3 \%(1 / 12)$ & $33.3 \%(2 / 6)$ & $50.0 \%(2 / 4)$ \\
\hline Other & $34.1 \%(15 / 44)$ & $49.3 \%(33 / 67)$ & $35.0 \%(21 / 60)$ & $43.9 \%(18 / 41)$ & $43.2 \%(16 / 37)$ & $26.1 \%(6 / 23)$ & $41.7 \%(5 / 12)$ & $22.2 \%(2 / 9)$ & $0.0 \%(0 / 6)$ & $60.0 \%(3 / 5)$ & $57.1 \%(4 / 7)$ \\
\hline
\end{tabular}

\begin{tabular}{|c|c|c|c|c|c|c|c|c|c|c|}
\hline Audience & Fall 2011 & Spring 2012 & Fall 2012 & Spring 2013 & Fall 2013 & Spring 2014 & Fall 2014 & Spring 2015 & Fall 2015 & Spring 2016 \\
\hline Professional & $50.0 \%(24 / 48)$ & $52.2 \%(48 / 92)$ & $24.2 \%(53 / 219)$ & $38.0 \%(135 / 355)$ & $39.4 \%(142 / 360)$ & $32.5 \%(156 / 480)$ & $39.8 \%(194 / 488)$ & $31.7 \%(189 / 597)$ & $43.9 \%(261 / 608)$ & $38.2 \%(289 / 756)$ \\
\hline General Academic & $30.8 \%(4 / 13)$ & $50.0 \%(16 / 32)$ & $59.0 \%(23 / 39)$ & $35.1 \%(26 / 74)$ & $39.5 \%(30 / 76)$ & $34.3 \%(34 / 99)$ & $45.5 \%(46 / 101)$ & $35.3 \%(47 / 133)$ & $50.0 \%(67 / 134)$ & $51.5 \%(85 / 165)$ \\
\hline Advanced Academic & $38.5 \%(45 / 117)$ & $36.1 \%(78 / 216)$ & $25.1 \%(94 / 374)$ & $26.2 \%(201 / 767)$ & $25.1 \%(194 / 773)$ & $20.6 \%(214 / 1037)$ & $25.7 \%(268 / 1042)$ & $21.6 \%(261 / 1206)$ & $29.5 \%(358 / 1212)$ & $33.6 \%(463 / 1378)$ \\
\hline Other & $0.0 \%(0 / 1)$ & $80.0 \%(4 / 5)$ & $28.6 \%(2 / 7)$ & $21.4 \%(3 / 14)$ & $28.6 \%(4 / 14)$ & $15.0 \%(3 / 20)$ & $30.0 \%(6 / 20)$ & $19.1 \%(4 / 21)$ & $33.3 \%(7 / 21)$ & $8.7 \%(2 / 23)$ \\
\hline
\end{tabular}

Table A4: Percent of Titles Used by Year from Publication, by Audience

\begin{tabular}{|c|c|c|c|c|c|c|c|c|c|c|c|}
\hline Audience & Year 1 & Year 2 & Year 3 & Year 4 & Year 5 & Year 6 & Year 7 & Year 8 & Year 9 & Year 10 & Year 11 \\
\hline Professional & $66.0 \%(266 / 403)$ & $62.5 \%(307 / 491)$ & $49.3 \%(204 / 414)$ & $37.8 \%(129 / 341)$ & $36.0 \%(94 / 261)$ & $31.1 \%(60 / 193)$ & $33.3 \%(45 / 135)$ & $40.6 \%(39 / 96)$ & $28.6 \%(20 / 70)$ & $28.6 \%(12 / 42)$ & $22.7 \%(5 / 22)$ \\
\hline General Academic & $83.6 \%(51 / 61)$ & $76.2 \%(83 / 109)$ & $50.5 \%(47 / 93)$ & $56.3 \%(40 / 71)$ & $40.0 \%(24 / 60)$ & $39.1 \%(18 / 46)$ & $35.5 \%(11 / 31)$ & $36.4 \%(8 / 22)$ & $33.3 \%(5 / 15)$ & $55.6 \%(5 / 9)$ & $80.0 \%(8 / 10)$ \\
\hline Advanced Academic & $58.1 \%(371 / 639)$ & $54.8 \%(470 / 858)$ & $37.2 \%(304 / 818)$ & $29.7 \%(202 / 680)$ & $27.6 \%(155 / 562)$ & $20.0 \%(94 / 471)$ & $21.6 \%(74 / 343)$ & $20.6 \%(47 / 228)$ & $19.1 \%(30 / 157)$ & $25.3 \%(22 / 87)$ & $18.6 \%(8 / 43)$ \\
\hline Other & $83.3 \%(5 / 6)$ & $80.0 \%(8 / 10)$ & $60.0 \%(9 / 15)$ & $16.7 \%(2 / 12)$ & $15.4 \%(2 / 13)$ & $16.7 \%(2 / 12)$ & $0.0 \%(0 / 8)$ & $25.0 \%(1 / 4)$ & $0.0 \%(0 / 3)$ & $0.0 \%(0 / 2)$ & $0.0 \%(0 / 1)$ \\
\hline
\end{tabular}


Table A5: Percent of Titles Used by Half Year, by Genre

\begin{tabular}{|c|c|c|c|c|c|c|c|c|c|c|}
\hline Genre & Fall 2011 & Spring 2012 & Fall 2012 & Spring 2013 & Fall 2013 & Spring 2014 & Fall 2014 & Spring 2015 & Fall 2015 & Spring 2016 \\
\hline Bibliography & $50.0 \%(3 / 6)$ & $59.1 \%(13 / 22)$ & $70.8 \%(17 / 24)$ & $48.3 \%(14 / 29)$ & $44.8 \%(13 / 29)$ & $34.4 \%(11 / 32)$ & $52.9 \%(18 / 34)$ & $40.5 \%(15 / 37)$ & $43.2 \%(16 / 37)$ & $33.3 \%(13 / 39)$ \\
\hline Encyclopedia & $0.0 \%(0 / 1)$ & $50.0 \%(1 / 2)$ & $100.0 \%(3 / 3)$ & $60.0 \%(3 / 5)$ & $80.0 \%(4 / 5)$ & $33.3 \%(2 / 6)$ & $57.1 \%(4 / 7)$ & $50.0 \%(5 / 10)$ & $60.0 \%(6 / 10)$ & $72.7 \%(8 / 11)$ \\
\hline \multicolumn{11}{|c|}{$\begin{array}{l}\text { Handbooks, Guides, } \\
\text { and Technical }\end{array}$} \\
\hline Manuals & $51.0 \%(25 / 49)$ & $49.5 \%(47 / 95)$ & $32.1 \%(36 / 112)$ & $33.7 \%(67 / 199)$ & $35.5 \%(72 / 203)$ & $30.8 \%(89 / 289)$ & $36.6 \%(107 / 292)$ & $26.1 \%(102 / 391)$ & $46.7 \%(185 / 396)$ & $40.5 \%(218 / 538)$ \\
\hline Proceedings & $20.0 \%(2 / 10)$ & $33.3 \%(5 / 15)$ & $17.2 \%(32 / 186)$ & $25.5 \%(109 / 428)$ & $24.8 \%(107 / 432)$ & $20.6 \%(109 / 529)$ & $28.1 \%(149 / 531)$ & $25.0 \%(143 / 573)$ & $20.8 \%(120 / 578)$ & $23.4 \%(144 / 616)$ \\
\hline Textbook & $46.2 \%(6 / 13)$ & $52.6 \%(10 / 19)$ & $34.5 \%(10 / 29)$ & $49.0 \%(25 / 51)$ & $44.2 \%(23 / 52)$ & $33.8 \%(26 / 77)$ & $51.3 \%(41 / 80)$ & $32.65 \%(32 / 98)$ & $53.5 \%$ (53/99) & $44.5 \%(53 / 119)$ \\
\hline Monographs & $29.2 \%(7 / 24)$ & $45.8 \%(22 / 48)$ & $23.9 \%(22 / 92)$ & $28.4 \%(55 / 194)$ & $28.6 \%(56 / 196)$ & $20.2 \%(55 / 273)$ & $24.7 \%(68 / 275)$ & $20.3 \%(71 / 350)$ & $36.4 \%(129 / 354)$ & $42.7 \%(177 / 415)$ \\
\hline Collections & $39.2 \%(29 / 74)$ & $32.6 \%(46 / 141)$ & $26.5 \%(50 / 189)$ & $30.5 \%(88 / 289)$ & $31.3 \%(91 / 291)$ & $26.9 \%(111 / 412)$ & $29.5 \%(122 / 414)$ & $26.6 \%(127 / 477)$ & $36.5 \%(175 / 480)$ & $38.1 \%(213 / 559)$ \\
\hline Other Reference & $100.0 \%(1 / 1)$ & $50.0 \%(1 / 2)$ & $50.0 \%(1 / 2)$ & $20.0 \%(1 / 5)$ & $40.0 \%(2 / 5)$ & $50.0 \%(3 / 6)$ & $83.3 \%(5 / 6)$ & $62.5 \%(5 / 8)$ & $50.0 \%(4 / 8)$ & $72.7 \%(8 / 11)$ \\
\hline Other & $0.0 \%(0 / 1)$ & $100.0 \%(1 / 1)$ & $50.0 \%(1 / 2)$ & $30.0 \%(3 / 10)$ & $20.0 \%(2 / 10)$ & $8.3 \%(1 / 12)$ & $0.0 \%(0 / 12)$ & $7.7 \%(1 / 13)$ & $38.5 \%(5 / 13)$ & $35.7 \%(5 / 14)$ \\
\hline
\end{tabular}

\begin{tabular}{|c|c|c|c|c|c|c|c|c|c|c|c|}
\hline Genre & Year 1 & Year 2 & Year 3 & Year 4 & Year 5 & Year 6 & Year 7 & Year 8 & Year 9 & Year 10 & Year 11 \\
\hline Bibliography & $100.0 \%(11 / 11)$ & $83.3 \%(25 / 3)$ & $50.0 \%(14 / 28)$ & $58.3 \%(14 / 24)$ & $43.5 \%(10 / 23)$ & $30.0 \%(6 / 20)$ & $28.6 \%(2 / 7)$ & $50.0 \%(4 / 8)$ & $62.5 \%(5 / 8)$ & $40.0 \%(2 / 5)$ & $80.0 \%(4 / 5)$ \\
\hline Encyclopedia & $60.0 \%(3 / 5)$ & $100.0 \%(7 / 7)$ & $100.0 \%(4 / 4)$ & $80.0 \%(4 / 5)$ & $83.3 \%(5 / 6)$ & $50.0 \%(3 / 6)$ & $50.0 \%(1 / 2)$ & $0.0 \%(0 / 1)$ & N/A & N/A & N/A \\
\hline \multicolumn{12}{|l|}{ Handbooks, Guides, } \\
\hline Technical Manuals & $71.8 \%(214 / 298)$ & $69.9 \%(237 / 339)$ & $42.0 \%(107 / 255)$ & $34.2 \%(64 / 187)$ & $31.6 \%(48 / 152)$ & $21.7 \%(26 / 120)$ & $26.4 \%(23 / 87)$ & $36.8 \%(21 / 57)$ & $20.4 \%(10 / 49)$ & $19.2 \%(5 / 26)$ & $36.4 \%(4 / 11)$ \\
\hline Proceedings & $52.5 \%(104 / 198)$ & $44.4 \%(134 / 302)$ & $39.4 \%(133 / 338)$ & $29.0 \%(101 / 348)$ & $25.3 \%(80 / 316)$ & $21.5 \%(59 / 274)$ & $19.4 \%(42 / 217)$ & $21.3 \%(34 / 160)$ & $17.3 \%(18 / 104)$ & $26.2 \%(16 / 61)$ & $12.5 \%(4 / 32)$ \\
\hline Textbook & $70.3 \%(45 / 64)$ & $75.0 \%(60 / 80)$ & $57.8 \%(41 / 71)$ & $50.0 \%(26 / 52)$ & $52.8 \%(19 / 36)$ & $55.2 \%(16 / 29)$ & $31.8 \%(7 / 22)$ & $35.3 \%(6 / 17)$ & $22.2 \%(2 / 9)$ & $0.0 \%(0 / 5)$ & $20.0 \%(1 / 5)$ \\
\hline Monographs & $63.1 \%(128 / 203)$ & $56.6 \%(154 / 272)$ & $44.2 \%(110 / 249)$ & $33.3 \%(63 / 189)$ & $27.0 \%(38 / 141)$ & $19.6 \%(21 / 107)$ & $27.2 \%(22 / 81)$ & $18.8 \%(9 / 48)$ & $21.2 \%(7 / 33)$ & $44.4 \%(8 / 18)$ & $25.0 \%(3 / 12)$ \\
\hline Collections & $56.3 \%(183 / 325)$ & $57.1 \%(241 / 422)$ & $38.1 \%(144 / 378)$ & $34.3 \%(97 / 283)$ & $33.8 \%(71 / 210)$ & $25.6 \%(41 / 160)$ & $33.0 \%(32 / 97)$ & $36.8 \%(21 / 57)$ & $31.7 \%(13 / 41)$ & $27.3 \%(6 / 22)$ & $37.5 \%(3 / 8)$ \\
\hline Other Reference & $100.0 \%(3 / 3)$ & $100.0 \%(6 / 6)$ & $83.3 \%(5 / 6)$ & $60.0 \%(3 / 5)$ & $66.7 \%(3 / 5)$ & $0.0 \%(0 / 1)$ & $0.0 \%(0 / 1)$ & $0.0 \%(0 / 1)$ & $0.0 \%(0 / 1)$ & $66.7 \%(2 / 3)$ & $66.7 \%(2 / 3)$ \\
\hline Other & $100.0 \%(2 / 2)$ & $40.0 \%(4 / 10)$ & $54.6 \%(6 / 11)$ & $9.1 \%(1 / 11)$ & $22.2 \%(2 / 9)$ & $40.0 \%(2 / 5)$ & $33.3 \%(1 / 3)$ & $0.0 \%(0 / 1)$ & $N / A$ & N/A & N/A \\
\hline
\end{tabular}

Table A7: Percent of Titles Used by Half Year, by LC Class Range

\begin{tabular}{|c|c|c|c|c|c|c|c|c|c|c|}
\hline LC Range & Fall 2011 & Spring 2012 & Fall 2012 & Spring 2013 & Fall 2013 & Spring 2014 & Fall 2014 & Spring 2015 & Fall 2015 & Spring 2016 \\
\hline AM & $25.0 \%(1 / 4)$ & $14.3 \%(1 / 7)$ & $50.0 \%(5 / 10)$ & $18.2 \%(2 / 11)$ & $27.3 \%(3 / 11)$ & $23.1 \%(6 / 26)$ & $53.9 \%(14 / 26)$ & $33.3 \%(11 / 33)$ & $57.6 \%(19 / 33)$ & $79.3 \%(42 / 53)$ \\
\hline $\mathbf{A Z}$ & N/A & $100.0 \%(1 / 1)$ & $33.3 \%(1 / 3)$ & $30.0 \%(3 / 10)$ & $50.0 \%(5 / 10)$ & $28.6 \%(4 / 14)$ & $28.6 \%(4 / 14)$ & $30.0 \%(6 / 20)$ & $55.0 \%(11 / 20)$ & $75.0 \%(18 / 24)$ \\
\hline CD & N/A & N/A & $0.0 \%(0 / 1)$ & $44.4 \%(4 / 9)$ & $33.3 \%(3 / 9)$ & $14.3 \%(2 / 14)$ & $50.0 \%(7 / 14)$ & $44.4 \%(8 / 18)$ & $61.1 \%(11 / 18)$ & $65.0 \%(13 / 20)$ \\
\hline HC & $16.7 \%(1 / 6)$ & $28.6 \%(2 / 7)$ & $6.7 \%(1 / 15)$ & $39.3 \%(11 / 28)$ & $14.3 \%(4 / 28)$ & $12.1 \%(4 / 33)$ & $18.2 \%(6 / 33)$ & $10.3 \%(4 / 39)$ & $20.5 \%(8 / 39)$ & $31.0 \%(13 / 42)$ \\
\hline HD & $31.7 \%(13 / 41)$ & $19.7 \%(14 / 71)$ & $12.4 \%(13 / 105)$ & $15.4 \%(27 / 175)$ & $16.0 \%(28 / 175)$ & $14.8 \%(34 / 230)$ & $19.6 \%(45 / 230)$ & $14.8 \%(39 / 264)$ & $16.7 \%(44 / 264)$ & $19.8 \%(68 / 344)$ \\
\hline HM & $43.8 \%(7 / 16)$ & $30.4 \%(7 / 23)$ & $30.8 \%(12 / 39)$ & $29.7 \%(19 / 64)$ & $27.7 \%(18 / 65)$ & $27.5 \%(25 / 91)$ & $32.6 \%(30 / 92)$ & $24.1 \%(26 / 108)$ & $30.3 \%(33 / 109)$ & $47.4 \%(64 / 135)$ \\
\hline K & $100.0 \%(2 / 2)$ & $33.3 \%(1 / 3)$ & $33.3 \%(1 / 3)$ & $58.8 \%(10 / 17)$ & $33.3 \%(6 / 18)$ & $17.2 \%(5 / 29)$ & $24.1 \%(7 / 29)$ & $18.9 \%(7 / 37)$ & $48.7 \%(18 / 37)$ & $50.0 \% 24 / 48$ \\
\hline $\mathbf{P}$ & $50.0 \%(3 / 6)$ & $69.2 \%(9 / 13)$ & $53.9 \%(7 / 13)$ & $40.0 \%(10 / 25)$ & $40.0 \%(10 / 25)$ & $20.0 \%(7 / 35)$ & $30.6 \%(11 / 36)$ & $30.8 \%(12 / 39)$ & $55.0 \%(22 / 40)$ & $54.6 \%(30 / 55)$ \\
\hline QA & $80.0 \%(4 / 5)$ & $28.6 \%(2 / 7)$ & $31.6 \%(6 / 19)$ & $45.0 \%(18 / 40)$ & $32.6 \%(14 / 43)$ & $24.5 \%(13 / 53)$ & $34.6 \%(18 / 52)$ & $32.8 \%(21 / 64)$ & $37.5 \%(24 / 64)$ & $25.6 \%(21 / 82)$ \\
\hline $\mathbf{T}$ & $23.8 \%(5 / 21)$ & $18.6 \%(8 / 43)$ & $11.6 \%(17 / 147)$ & $17.3 \%(64 / 369)$ & $19.1 \%(71 / 371)$ & $16.7 \%(77 / 461)$ & $22.5 \%(104 / 462)$ & $17.5 \%(89 / 510)$ & $17.2 \%(88 / 513) 2$ & $20.4 \%(109 / 534)$ \\
\hline Z & $47.2 \%(25 / 53)$ & $61.8 \%(81 / 131)$ & $38.9 \%(81 / 208)$ & $41.7 \%(138 / 331)$ & $47.3 \%(158 / 334)$ & $35.4 \%(168 / 474)$ & $40.8 \%(198 / 485)$ & $35.3 \%(220 / 624)$ & $49.9 \%(316 / 633) 4$ & $45.1 \%(332 / 736)$ \\
\hline ZA & $58.3 \%(7 / 12)$ & $57.1 \%(12 / 21)$ & $35.1 \%(20 / 57)$ & $47.3 \%(43 / 91)$ & $35.1 \%(33 / 94)$ & $39.4 \%(48 / 122)$ & $43.9 \%(54 / 123)$ & $31.1 \%(43 / 138)$ & $49.6 \%(69 / 139)$ & $41.3 \%(64 / 155)$ \\
\hline Other & $38.5 \%(5 / 13)$ & $44.4 \%(8 / 18)$ & $42.1 \%(8 / 19)$ & $40.0 \%(16 / 40)$ & $42.5 \%(17 / 40)$ & $25.9 \%(14 / 54)$ & $29.1 \%(16 / 55)$ & $23.8 \%(15 / 63)$ & $45.5 \%(30 / 66)$ & $43.6 \%(41 / 94)$ \\
\hline
\end{tabular}

Table A8: Percent of Titles Used by Year from Publication, by LC Class Range

\begin{tabular}{|c|c|c|c|c|c|c|c|c|c|c|c|}
\hline LC Range & Year 1 & Year 2 & Year 3 & Year 4 & Year 5 & Year 6 & Year 7 & Year 8 & Year 9 & Year 10 & Year 11 \\
\hline$\overline{A M}$ & $82.8 \%(24 / 29)$ & $80.0 \%(24 / 30)$ & $68.0 \%(17 / 25)$ & $63.6 \%(7 / 11)$ & $33.3 \%(3 / 9)$ & $70.0 \%(7 / 10)$ & $37.5 \%(3 / 8)$ & $42.9 \%(3 / 7)$ & $40.0 \%(2 / 5)$ & $33.3 \%(1 / 3)$ & N/A \\
\hline AZ & $50.0 \%(6 / 12)$ & $72.2 \%(13 / 18)$ & $53.9 \%(7 / 13)$ & $69.2 \%(9 / 13)$ & $83.3 \%(5 / 6)$ & $0.0 \%(0 / 1)$ & $100.0 \%(2 / 2)$ & $50.0 \%(1 / 2)$ & $50.0 \%(1 / 2)$ & $50.0 \%(1 / 2)$ & N/A \\
\hline$C D$ & $100.0 \%(11 / 11)$ & $88.9 \%(16 / 18)$ & $46.7 \%(7 / 15)$ & $22.2 \%(2 / 9)$ & $42.9 \%(3 / 7)$ & $100.0 \%(1 / 1)$ & $100.0 \%(1 / 1)$ & N/A & N/A & N/A & $N / A$ \\
\hline $\mathrm{HC}$ & $45.5 \%(10 / 22)$ & $40.0 \%(10 / 25)$ & $45.0 \%(9 / 20)$ & $10.5 \%(2 / 19)$ & $50.0 \%(5 / 10)$ & $0.0 \%(0 / 12)$ & $21.4 \%(3 / 14)$ & $28.6 \%(4 / 14)$ & $18.2 \%(2 / 11)$ & $30.0 \%(3 / 10)$ & $16.7 \%(1 / 6)$ \\
\hline HD & $41.8 \%(61 / 146)$ & $36.3 \%(70 / 193)$ & $23.7 \%(44 / 186)$ & $19.3 \%(28 / 145)$ & $19.4 \%(28 / 144)$ & $11.9 \%(14 / 118)$ & $19.3 \%(17 / 88)$ & $19.6 \%(11 / 56)$ & $10.4 \%(5 / 48)$ & $25.0 \%(6 / 24)$ & $14.3 \%(2 / 14)$ \\
\hline HM & $59.7 \%(40 / 67)$ & $66.3 \%(57 / 86)$ & $42.3 \%(30 / 71)$ & $32.8 \%(20 / 61)$ & $30.4 \%(14 / 46)$ & $25.6 \%(11 / 43)$ & $35.5 \%(11 / 31)$ & $52.6 \%(10 / 19)$ & $26.7 \%(4 / 15)$ & $55.6 \%(5 / 9)$ & $25.0 \%(1 / 4)$ \\
\hline $\mathrm{K}$ & $70.6 \%(12 / 17)$ & $66.7 \%(22 / 33)$ & $58.1 \%(18 / 31)$ & $31.8 \%(7 / 22)$ & $33.3 \%(4 / 12)$ & $30.0 \%(3 / 10)$ & $33.3 \%(1 / 3)$ & $33.3 \%(1 / 3)$ & $0.0 \%(0 / 3)$ & $0.0 \%(0 / 1)$ & $100.0 \%(1 / 1)$ \\
\hline $\mathbf{P}$ & $86.4 \%(19 / 22)$ & $79.6 \%(35 / 44)$ & $57.6 \%(19 / 33)$ & $33.3 \%(9 / 27)$ & $50.0 \%(11 / 22)$ & $23.1 \%(3 / 13)$ & $50.0 \%(3 / 6)$ & $33.3 \%(1 / 3)$ & $66.7 \%(2 / 3)$ & $0.0 \%(0 / 2)$ & N/A \\
\hline QA & $50.0 \%(16 / 32)$ & $55.1 \%(27 / 49)$ & $35.9 \%(19 / 53)$ & $34.9 \%(15 / 43)$ & $30.0 \%(9 / 30)$ & $38.1 \%(8 / 21)$ & $41.2 \%(7 / 17)$ & $54.6 \%(6 / 11)$ & $33.3 \%(2 / 6)$ & $50.0 \%(1 / 2)$ & $100.0 \%(1 / 1)$ \\
\hline $\begin{array}{lllllll} & \end{array}$ & $42.9 \%(90 / 210)$ & $37.0 \%(113 / 305)$ & $34.8 \%(112 / 322)$ & $24.1 \%(78 / 324)$ & $21.2 \%(57 / 269)$ & $17.2 \%(38 / 221)$ & $14.1 \%(23 / 163)$ & $9.8 \%(11 / 112)$ & $3.0 \%(2 / 66)$ & $5.3 \%(2 / 38)$ & $5.9 \%(1 / 17)$ \\
\hline$z$ & $75.9 \%(314 / 414)$ & $73.8 \%(372 / 504)$ & $48.8 \%(203 / 416)$ & $46.1 \%(142 / 308)$ & $38.8 \%(95 / 245)$ & $35.0 \%(69 / 197)$ & $34.4 \%(45 / 131)$ & $36.7 \%(33 / 90)$ & $36.9 \%(24 / 65)$ & $32.4 \%(12 / 37)$ & $48.0 \%(12 / 25)$ \\
\hline $\mathrm{ZA}$ & $65.8 \%(50 / 76)$ & $65.1 \%(67 / 103)$ & $52.1 \%(50 / 96)$ & $46.9 \%(38 / 81)$ & $50.8 \%(33 / 65)$ & $37.0 \%(20 / 54)$ & $33.3 \%(14 / 42)$ & $46.2 \%(12 / 26)$ & $55.6 \%(10 / 18)$ & $70.0 \%(7 / 10)$ & $28.6 \%(2 / 7)$ \\
\hline Other & $78.4 \%(40 / 51)$ & $70.0 \%(42 / 60)$ & $49.2 \%(29 / 59)$ & $39.0 \%(16 / 41)$ & $25.8 \%(8 / 31)$ & $0.0 \%(0 / 21)$ & $0.0 \%(0 / 11)$ & $28.6 \%(2 / 7)$ & $33.3 \%(1 / 3)$ & $50.0 \%(1 / 2)$ & $0.0 \%(0 / 1)$ \\
\hline
\end{tabular}

Table A9: Percent of Titles Used by Year from Publication, by Publication Year

\begin{tabular}{|c|c|c|c|c|c|c|c|c|c|c|c|}
\hline $\begin{array}{l}\text { Publication Year } \\
\end{array}$ & Year 1 & Year 2 & Year 3 & $\begin{array}{ll}\text { Year } 4 \\
\end{array}$ & Year 5 & Year 6 & Year 7 & $\begin{array}{ll}\text { Year } 8 \\
\end{array}$ & Year 9 & Year 10 & Year 11 \\
\hline 2006 & N/A & $\mathrm{N} / \mathrm{A}$ & N/A & N/A & N/A & $0.0 \%(0 / 7)$ & $15.2 \%(5 / 33)$ & $39.1 \%(25 / 64)$ & $36.4 \%(24 / 66)$ & $32.9 \%(23 / 70)$ & $6 \%(21 / 76)$ \\
\hline 2007 & N/A & N/A & N/A & N/A & $44.4 \%(4 / 9)$ & $32.4 \%(11 / 34)$ & $40.6 \%(26 / 64)$ & $32.4 \%(22 / 68)$ & $23.5 \%(16 / 68)$ & $22.9 \%(16 / 70)$ & N/A \\
\hline 2008 & N/A & N/A & N/A & $38.9 \%(7 / 18)$ & $30.2 \%(16 / 53)$ & $28.9 \%(28 / 97)$ & $24.0 \%(24 / 100)$ & $21.8 \%(22 / 101)$ & $13.5 \%(15 / 111)$ & N/A & N/A \\
\hline 2009 & N/A & $N / A$ & $27.6 \%(8 / 29)$ & $34.9 \%(23 / 66)$ & $32.4 \%(36 / 111)$ & $25.7 \%(29 / 113)$ & $18.4 \%(21 / 114)$ & $22.2 \%(26 / 117)$ & N/A & N/A & N/A \\
\hline 2010 & N/A & $39.1 \%(25 / 64)$ & $30.6 \%(41 / 134)$ & $36.1 \%(66 / 183)$ & $35.9 \%(70 / 195)$ & $25.8 \%(50 / 194)$ & $26.2 \%(54 / 206)$ & N/A & N/A & N/A & N/A \\
\hline 2011 & $55.1 \%(27 / 49)$ & $50.6 \%(91 / 180)$ & $46.9 \%(113 / 241)$ & $38.7 \%(101 / 261)$ & $33.7 \%(90 / 267)$ & $20.2 \%(56 / 277)$ & N/A & N/A & N/A & N/A & N/A \\
\hline 2012 & $46.0 \%(63 / 137)$ & $57.1 \%(129 / 226)$ & $41.5 \%(100 / 241)$ & $32.6 \%(79 / 242)$ & $22.6 \%(59 / 261)$ & N/A & N/A & N/A & N/A & N/A & N/A \\
\hline 2013 & $58.3 \%(137 / 235)$ & $52.2 \%(170 / 326)$ & $55.6 \%(189 / 340)$ & $29.0 \%(97 / 334)$ & N/A & N/A & N/A & N/A & N/A & N/A & N/A \\
\hline 2014 & $59.0 \%(164 / 278)$ & $62.3 \%(208 / 334)$ & $31.8 \%(113 / 355)$ & N/A & N/A & N/A & N/A & N/A & N/A & N/A & N/A \\
\hline 2015 & $69.9 \%(167 / 239)$ & $72.5 \%(245 / 338)$ & N/A & $\mathrm{N} / \mathrm{A}$ & N/A & N/A & N/A & N/A & N/A & N/A & $\mathrm{N} / \mathrm{A}$ \\
\hline 2016 & $79.0 \%(135 / 171)$ & $\mathrm{N} / \mathrm{A}$ & N/A & N/A & N/A & N/A & N/A & N/A & N/A & N/A & $\mathrm{N} / \mathrm{A}$ \\
\hline
\end{tabular}




\section{Appendix B}

This appendix includes tables of summary descriptive statistics underlying the top quartile index scores shown in table 3 of the text. For each category, table B1 shows the total number of top-quartile titles, plus the percentage of titles of the total top quartile titles that category represented. Because some publishers did not have sufficient titles to break down into the top quartile analysis, table B2 shows the total number of titles in the category overall for the publishers included, with the percentages of titles it represented in the collection overall. The relative usage index scores in table 3 of the text are then calculated by dividing the percentages in table B1 by the percentages in table B2.

\begin{tabular}{|c|c|c|c|c|c|c|c|c|c|c|c|}
\hline Category & Year 1 & Year 2 & Year 3 & Year 4 & Year 5 & Year 6 & Year 7 & Year 8 & Year 9 & Year 10 & Year 11 \\
\hline \multicolumn{12}{|l|}{ Total Audience } \\
\hline Professional & $74(38.5 \%)$ & $76(34.7 \%)$ & $52(36.6 \%)$ & $32(34.8 \%)$ & $28(40.6 \%)$ & $17(38.6 \%)$ & $11(30.6 \%)$ & $8(30.8 \%)$ & $3(23.1 \%)$ & $3(25.0 \%)$ & $0(0.0 \%)$ \\
\hline General Academic & $17(8.9 \%)$ & $29(13.2 \%)$ & $12(8.5 \%)$ & $9(9.8 \%)$ & $7(10.1 \%)$ & 4 (9.1\%) & $3(8.3 \%)$ & $2(7.7 \%)$ & $2(16.7 \%)$ & $2(16.7 \%)$ & $2(40.0 \%)$ \\
\hline Advanced Academic & $100(52.1 \%)$ & $113(51.6 \%)$ & $76(53.5 \%)$ & $51(55.4 \%)$ & $34(49.3 \%)$ & $23(52.3 \%)$ & $22(61.1 \%)$ & $16(61.5 \%)$ & $7(58.3 \%)$ & $7(58.3 \%)$ & $3(60.0 \%)$ \\
\hline Other & $1(0.5 \%)$ & $1(0.5 \%)$ & $2(1.4 \%)$ & $0(0.0 \%)$ & $0(0.0 \%)$ & $0(0.0 \%)$ & $0(0.0 \%)$ & $0(0.0 \%)$ & $0(0.0 \%)$ & $0(0.0 \%)$ & $0(0.0 \%)$ \\
\hline \multicolumn{12}{|l|}{ Total Genre } \\
\hline Bibliography & $2(1.0 \%)$ & $5(2.3 \%)$ & $2(1.4 \%)$ & $4(4.3 \%)$ & $2(2.9 \%)$ & $2(4.5 \%)$ & $1(2.8 \%)$ & $0(0.0 \%)$ & $1(7.7 \%)$ & $1(8.3 \%)$ & $1(20.0 \%)$ \\
\hline Encyclopedia & $3(1.6 \%)$ & $4(1.8 \%)$ & $3(2.1 \%)$ & $2(2.2 \%)$ & $0(0.0 \%)$ & $0(0.0 \%)$ & $0(0.0 \%)$ & $0(0.0 \%)$ & $0(0.0 \%)$ & $0(0.0 \%)$ & $0(0.0 \%)$ \\
\hline \multicolumn{12}{|l|}{ Handbooks, Guides, anc } \\
\hline Technical Manuals & $67(34.9 \%)$ & 55 (25.1\%) & $35(24.6 \%)$ & $19(20.7 \%)$ & $16(23.2 \%)$ & $5(11.4 \%)$ & $7(19.4 \%)$ & $5(19.2 \%)$ & $2(15.4 \%)$ & $2(16.7 \%)$ & $0(0.0 \%)$ \\
\hline Proceedings & $30(15.6 \%)$ & 34 (15.5\%) & $28(19.7 \%)$ & $26(28.3 \%)$ & $23(33.3 \%)$ & $12(27.3 \%)$ & $10(27.8 \%)$ & $8(30.8 \%)$ & $6(46.2 \%)$ & $4(33.3 \%)$ & $1(20.0 \%)$ \\
\hline Textbooks & $13(6.8 \%)$ & 20 (9.1\%) & $16(11.3 \%)$ & $7(7.6 \%)$ & $3(4.3 \%)$ & $5(11.4 \%)$ & $2(5.6 \%)$ & $2(7.7 \%)$ & $0(0.0 \%)$ & $0(0.0 \%)$ & $0(0.0 \%)$ \\
\hline Other Reference & $1(0.5 \%)$ & $2(0.9 \%)$ & $2(1.4 \%)$ & $1(1.1 \%)$ & $0(0.0 \%)$ & $0(0.0 \%)$ & $0(0.0 \%)$ & $0(0.0 \%)$ & $0(0.0 \%)$ & $0(0.0 \%)$ & $0(0.0 \%)$ \\
\hline Other & $1(0.5 \%)$ & $0(0.0 \%)$ & $1(0.7 \%)$ & $0(0.0 \%)$ & $0(0.0 \%)$ & $1(2.3 \%)$ & $0(0.0 \%)$ & $0(0.0 \%)$ & $0(0.0 \%)$ & $0(0.0 \%)$ & $0(0.0 \%)$ \\
\hline Monographs & 27 (14.1\%) & 32 (14.6\%) & $15(10.6 \%)$ & 12 (13.0\%) & 8 (11.6\%) & 4 (9.1\%) & 4 (11.1\%) & 2 (7.7\%) & 1 (7.7\%) & $3(25.0 \%)$ & $2(40.0 \%)$ \\
\hline Collections & $48(25.0 \%)$ & $67(30.6 \%)$ & $40(28.2 \%)$ & $21(22.8 \%)$ & $17(24.6 \%)$ & $15(34.1 \%)$ & $12(33.3 \%)$ & $9(34.6 \%)$ & $3(23.1 \%)$ & $2(16.7 \%)$ & $1(20.0 \%)$ \\
\hline \multicolumn{12}{|l|}{ Total Class } \\
\hline AM & 11 (5.7\%) & $6(2.7 \%)$ & $2(1.4 \%)$ & 1 (1.1\%) & $1(1.4 \%)$ & 0 (0.0\%) & $0(0.0 \%)$ & $1(3.8 \%)$ & 1 (7.7\%) & $0(0.0 \%)$ & $0(0.0 \%)$ \\
\hline AZ & $1(0.5 \%)$ & $3(1.4 \%)$ & $2(1.4 \%)$ & $1(1.1 \%)$ & $0(0.0 \%)$ & $0(0.0 \%)$ & $1(2.8 \%)$ & $0(0.0 \%)$ & $0(0.0 \%)$ & $1(8.3 \%)$ & $0(0.0 \%)$ \\
\hline CD & $5(2.6 \%)$ & $3(1.4 \%)$ & $2(1.4 \%)$ & $0(0.0 \%)$ & $0(0.0 \%)$ & 0 (0.0\%) & $0(0.0 \%)$ & $0(0.0 \%)$ & $0(0.0 \%)$ & $0(0.0 \%)$ & $0(0.0 \%)$ \\
\hline $\mathrm{HC}$ & $2(1.0 \%)$ & 2 (0.9\%) & $1(0.7 \%)$ & $0(0.0 \%)$ & 0 (0.0\%) & $0(0.0 \%)$ & $1(2.8 \%)$ & $0(0.0 \%)$ & 2 (15.4\%) & 1 (8.3\%) & $0(0.0 \%)$ \\
\hline HD & $16(8.3 \%)$ & $15(6.8 \%)$ & 10 (7.0\%) & 5 (5.4\%) & $4(5.8 \%)$ & $2(4.5 \%)$ & $2(5.6 \%)$ & 2 (7.7\%) & 1 (7.7\%) & 2 (16.7\%) & $1(20.0 \%)$ \\
\hline HM & $11(5.7 \%)$ & $18(8.2 \%)$ & 12 (8.5\%) & $4(4.3 \%)$ & $4(5.8 \%)$ & 4 (9.1\%) & 4 (11.1\%) & $6(23.1 \%)$ & $1(7.7 \%)$ & 1 (8.3\%) & $1(20.0 \%)$ \\
\hline $\mathrm{K}$ & $5(2.6 \%)$ & $3(1.4 \%)$ & 3 (2.1\%) & $0(0.0 \%)$ & 2 (2.9\%) & $0(0.0 \%)$ & $1(2.8 \%)$ & $0(0.0 \%)$ & $0(0.0 \%)$ & $0(0.0 \%)$ & $0(0.0 \%)$ \\
\hline $\mathbf{P}$ & $4(2.1 \%)$ & $9(4.1 \%)$ & $5(3.5 \%)$ & $4(4.3 \%)$ & $1(1.4 \%)$ & $0(0.0 \%)$ & $0(0.0 \%)$ & $0(0.0 \%)$ & $0(0.0 \%)$ & $0(0.0 \%)$ & $0(0.0 \%)$ \\
\hline QA & $2(1.0 \%)$ & $10(4.6 \%)$ & $4(2.8 \%)$ & $3(3.3 \%)$ & $5(7.2 \%)$ & $1(2.3 \%)$ & $2(5.6 \%)$ & $3(11.5 \%)$ & $0(0.0 \%)$ & $0(0.0 \%)$ & $0(0.0 \%)$ \\
\hline $\mathbf{T}$ & $18(9.4 \%)$ & $20(9.1 \%)$ & $19(13.4 \%)$ & $17(18.5 \%)$ & $13(18.8 \%)$ & $11(25.0 \%)$ & 5 (13.9\%) & $2(7.7 \%)$ & $0(0.0 \%)$ & $0(0.0 \%)$ & $1(20.0 \%)$ \\
\hline Z & 94 (49.0\%) & 105 (47.9\%) & 63 (44.4\%) & 44 (47.8\%) & 27 (39.1\%) & $18(40.9 \%)$ & $18(50.0 \%)$ & $9(34.6 \%)$ & $6(46.2 \%)$ & 4 (33.3\%) & $1(20.0 \%)$ \\
\hline ZA & $12(6.3 \%)$ & $18(8.2 \%)$ & 15 (10.6\%) & $9(9.8 \%)$ & 8 (11.6\%) & $8(18.2 \%)$ & $2(5.6 \%)$ & 2 (7.7\%) & 2 (15.4\%) & 2 (16.7\%) & $1(20.0 \%)$ \\
\hline Other & $11(5.7 \%)$ & $7(3.2 \%)$ & $4(2.8 \%)$ & $4(4.3 \%)$ & $4(5.8 \%)$ & $0(0.0 \%)$ & $0(0.0 \%)$ & $1(3.8 \%)$ & $0(0.0 \%)$ & $1(8.3 \%)$ & $0(0.0 \%)$ \\
\hline
\end{tabular}

Table B2: Total Titles for Publishers in Top-Quartile Anaylsis and Percentage of All Titles

\begin{tabular}{|c|c|c|c|c|c|c|c|c|c|c|c|}
\hline Category & Year 1 & Year 2 & Year 3 & Year 4 & Year 5 & Year 6 & Year 7 & Year 8 & Year 9 & Year 10 & Year 11 \\
\hline \multicolumn{12}{|l|}{ Audience } \\
\hline Professional & 397 (37.5\%) & $485(34.6 \%)$ & $408(31.9 \%)$ & $336(31.6 \%)$ & 257 (29.9\%) & $192(28.4 \%)$ & $125(25.6 \%)$ & 96 (40.9\%) & $54(28.0 \%)$ & $42(33.3 \%)$ & $15(37.5 \%)$ \\
\hline General Academic & $58(5.5 \%)$ & $100(7.1 \%)$ & $86(6.7 \%)$ & $64(6.0 \%)$ & $51(5.9 \%)$ & $38(5.6 \%)$ & $25(5.1 \%)$ & $18(7.7 \%)$ & $9(4.7 \%)$ & $7(5.6 \%)$ & $4(10.0 \%)$ \\
\hline Advanced Academic & $597(56.4 \%)$ & 805 (57.5\%) & $772(60.4 \%)$ & $652(61.4 \%)$ & $542(63.1 \%)$ & $438(64.8 \%)$ & $334(68.3 \%)$ & $118(50.2 \%)$ & $127(65.8 \%)$ & 75 (59.5\%) & $20(50.0 \%)$ \\
\hline Other & $6(0.6 \%)$ & $10(0.7 \%)$ & $13(1.0 \%)$ & $10(0.9 \%)$ & $9(1.0 \%)$ & $8(1.2 \%)$ & $5(1.0 \%)$ & $3(1.3 \%)$ & $3(1.6 \%)$ & $2(1.6 \%)$ & $1(2.5 \%)$ \\
\hline \multicolumn{12}{|l|}{$\overline{\text { Genr }}$} \\
\hline Bibliography & $11(1.0 \%)$ & $26(1.9 \%)$ & 24 (1.9\%) & $20(1.9 \%)$ & $19(2.2 \%)$ & $15(2.2 \%)$ & $7(1.4 \%)$ & 7 (3.0\%) & $7(3.6 \%)$ & $5(4.0 \%)$ & $3(7.5 \%)$ \\
\hline Encyclopedia & $5(0.5 \%)$ & $7(0.5 \%)$ & $4(0.3 \%)$ & $4(0.4 \%)$ & $3(0.3 \%)$ & $2(0.3 \%)$ & $1(0.2 \%)$ & $0(0.0 \%)$ & $0(0.0 \%)$ & $0(0.0 \%)$ & $0(0.0 \%)$ \\
\hline \multicolumn{12}{|l|}{ Handbooks, Guides, anc } \\
\hline Technical Manuals & $292(27.6 \%)$ & $333(23.8 \%)$ & 249 (19.\%) & $182(17.1 \%)$ & $147(17.1 \%)$ & $118(17.5 \%)$ & $76(15.5 \%)$ & $56(23.8 \%)$ & $29(15.0 \%)$ & $26(20.6 \%)$ & $4(10.0 \%)$ \\
\hline Proceedings & $188(17.8 \%)$ & $292(20.9 \%)$ & $330(25.8 \%)$ & $343(32.3 \%)$ & $312(36.3 \%)$ & 267 (39.5\%) & $215(44.0 \%)$ & $71(30.2 \%)$ & $102(52.8 \%)$ & $60(47.6 \%)$ & $19(47.5 \%)$ \\
\hline Textbooks & $59(5.6 \%)$ & $75(5.4 \%)$ & $69(5.4 \%)$ & $50(4.7 \%)$ & 35 (4.1\%) & $28(4.1 \%)$ & $18(3.7 \%)$ & $16(6.8 \%)$ & $6(3.1 \%)$ & $4(3.2 \%)$ & $2(5.0 \%)$ \\
\hline Other Reference & $3(0.3 \%)$ & $6(0.4 \%)$ & $6(0.5 \%)$ & $5(0.5 \%)$ & $3(0.3 \%)$ & $1(0.1 \%)$ & $1(0.2 \%)$ & $1(0.4 \%)$ & $1(0.5 \%)$ & $1(0.8 \%)$ & $0(0.0 \%)$ \\
\hline Other & $2(0.2 \%)$ & $7(0.5 \%)$ & $8(0.6 \%)$ & $8(0.8 \%)$ & $8(0.9 \%)$ & $5(0.7 \%)$ & $3(0.6 \%)$ & $1(0.4 \%)$ & $0(0.0 \%)$ & $0(0.0 \%)$ & 0 (0.0\%) \\
\hline Monographs & $192(18.1 \%)$ & 254 (18.1\%) & $234(18.3 \%)$ & $178(16.8 \%)$ & $130(15.1 \%)$ & $90(13.3 \%)$ & $77(15.7 \%)$ & $34(14.5 \%)$ & $24(12.4 \%)$ & $15(11.9 \%)$ & $9(22.5 \%)$ \\
\hline Collections & $306(28.9 \%)$ & $400(28.6 \%)$ & $355(27.8 \%)$ & $272(25.6 \%)$ & $202(23.5 \%)$ & $150(22.2 \%)$ & $91(18.6 \%)$ & $49(20.9 \%)$ & $24(12.4 \%)$ & $15(11.9 \%)$ & $3(7.5 \%)$ \\
\hline \multicolumn{12}{|l|}{$\mathrm{Cla}$} \\
\hline AM & $28(2.6 \%)$ & $28(2.0 \%)$ & $23(1.8 \%)$ & $10(0.9 \%)$ & $9(1.0 \%)$ & $10(1.5 \%)$ & $6(1.2 \%)$ & $6(2.6 \%)$ & $3(1.6 \%)$ & $3(2.4 \%)$ & $0(0.0 \%)$ \\
\hline$A Z$ & $9(0.9 \%)$ & 15 (1.1\%) & 11 (0.9\%) & $11(1.0 \%)$ & $5(0.6 \%)$ & $0(0.0 \%)$ & $2(0.4 \%)$ & 0 (0.0\%) & $1(0.5 \%)$ & $1(0.8 \%)$ & $0(0.0 \%)$ \\
\hline$C D$ & $11(1.0 \%)$ & $18(1.3 \%)$ & 15 (1.2\%) & $9(0.8 \%)$ & 7 (0.8\%) & 1 (0.1\%) & $1(0.2 \%)$ & $0(0.0 \%)$ & $0(0.0 \%)$ & $0(0.0 \%)$ & $0(0.0 \%)$ \\
\hline $\mathrm{HC}$ & $22(2.1 \%)$ & $25(1.8 \%)$ & $20(1.6 \%)$ & $19(1.8 \%)$ & $10(1.2 \%)$ & $12(1.8 \%)$ & $14(2.9 \%)$ & $13(5.5 \%)$ & $8(4.1 \%)$ & $8(6.3 \%)$ & $5(12.5 \%)$ \\
\hline HD & $142(13.4 \%)$ & 190 (13.6\%) & 184 (14.4\%) & 143 (13.5\%) & 141 (16.4\%) & $118(17.5 \%)$ & $80(16.4 \%)$ & 45 (19.1\%) & 27 (14.0\%) & 20 (15.9\%) & $8(20.0 \%)$ \\
\hline HM & $66(6.2 \%)$ & 84 (6.0\%) & $70(5.5 \%)$ & $60(5.6 \%)$ & 45 (5.2\%) & $42(6.2 \%)$ & 29 (5.9\%) & $16(6.8 \%)$ & $12(6.2 \%)$ & 7 (5.6\%) & $3(7.5 \%)$ \\
\hline K & 15 (1.4\%) & $26(1.9 \%)$ & $22(1.7 \%)$ & $15(1.4 \%)$ & $8(0.9 \%)$ & $8(1.2 \%)$ & $3(0.6 \%)$ & $3(1.3 \%)$ & $3(1.6 \%)$ & $1(0.8 \%)$ & $0(0.0 \%)$ \\
\hline $\mathbf{P}$ & 20 (1.9\%) & 39 (2.8\%) & $29(2.3 \%)$ & 25 (2.4\%) & $19(2.2 \%)$ & $11(1.6 \%)$ & $6(1.2 \%)$ & $3(1.3 \%)$ & $3(1.6 \%)$ & $2(1.6 \%)$ & $0(0.0 \%)$ \\
\hline QA & $30(2.8 \%)$ & $48(3.4 \%)$ & 50 (3.9\%) & $41(3.9 \%)$ & 29 (3.4\%) & $20(3.0 \%)$ & 15 (3.1\%) & $7(3.0 \%)$ & $5(2.6 \%)$ & $2(1.6 \%)$ & $0(0.0 \%)$ \\
\hline $\mathbf{T}$ & 199 (18.8\%) & 296 (21.1\%) & 318 (24.9\%) & $321(30.2 \%)$ & 267 (31.1\%) & 219 (32.4\%) & $158(32.3 \%)$ & $44(18.7 \%)$ & $62(32.1 \%)$ & $38(30.2 \%)$ & $8(20.0 \%)$ \\
\hline$z$ & 397 (37.5\%) & $476(34.0 \%)$ & $390(30.5 \%)$ & $290(27.3 \%)$ & $228(26.5 \%)$ & $162(24.0 \%)$ & $124(25.4 \%)$ & $72(30.6 \%)$ & $51(26.4 \%)$ & $32(25.4 \%)$ & $10(25.0 \%)$ \\
\hline ZA & $73(6.9 \%)$ & 99 (7.1\%) & $92(7.2 \%)$ & 79 (7.4\%) & $63(7.3 \%)$ & $54(8.0 \%)$ & 41 (8.4\%) & $20(8.5 \%)$ & $16(8.3 \%)$ & 10 (7.9\%) & $5(12.5 \%)$ \\
\hline Other & $46(4.3 \%)$ & $56(4.0 \%)$ & 55 (4.3\%) & $39(3.7 \%)$ & $28(3.3 \%)$ & $19(2.8 \%)$ & $10(2.0 \%)$ & $6(2.6 \%)$ & $2(1.0 \%)$ & $2(1.6 \%)$ & $1(2.5 \%)$ \\
\hline
\end{tabular}

